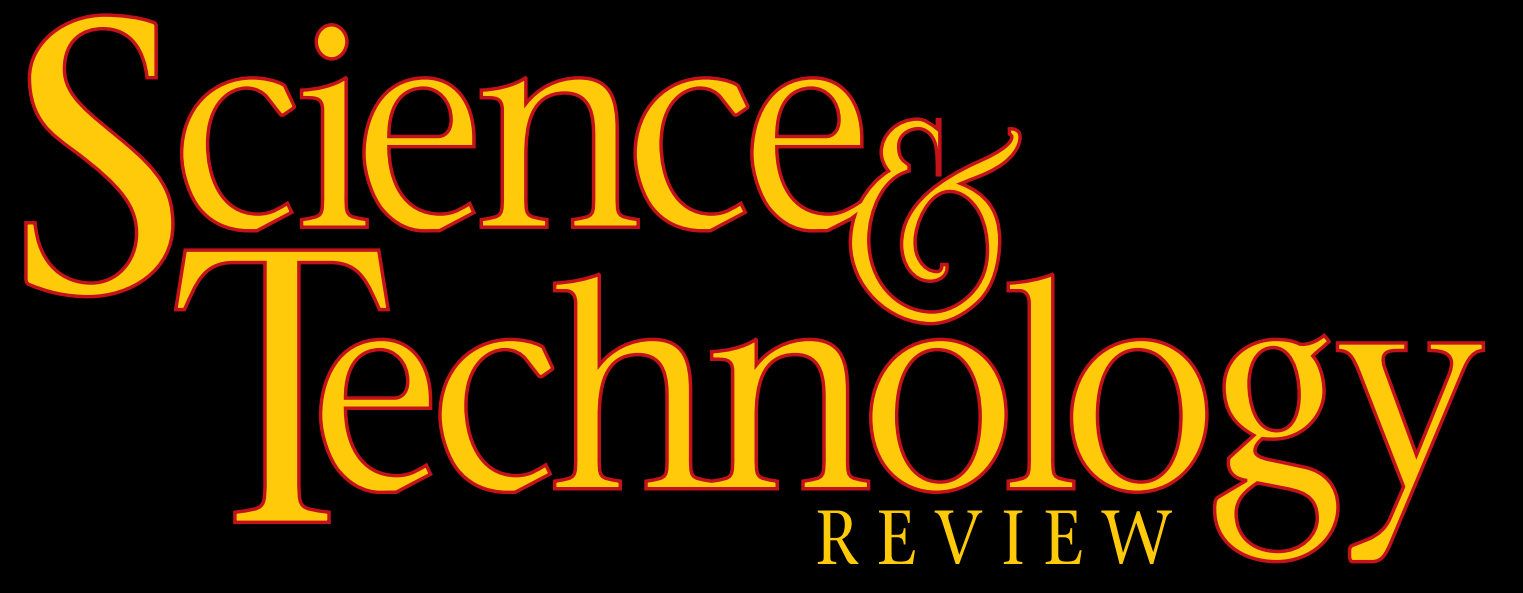

September 1999

Predicting

How Weapon

Materals Age

Also in this issue:

- Determining Radiation Effects to Chernobyl Cleanup Workers

- National Ignition Facility's Target

Chamber Makes Its Debut 
A significant part of Livermore's work in support of the Department of Energy's Stockpile Stewardship Program is collecting data and developing computer models to predict how components in a stockpiled weapon interact and how rapidly they age. $S \& T R$ 's report on this research begins on $\mathrm{p} .4$. On the cover is an image from one aspect of this research-the computed density distribution of ultrafine insensitive high-explosive powder (TATB) in a weapon component. This research aims to correlate observed density variations with the material's age and its performance with measured density variations.

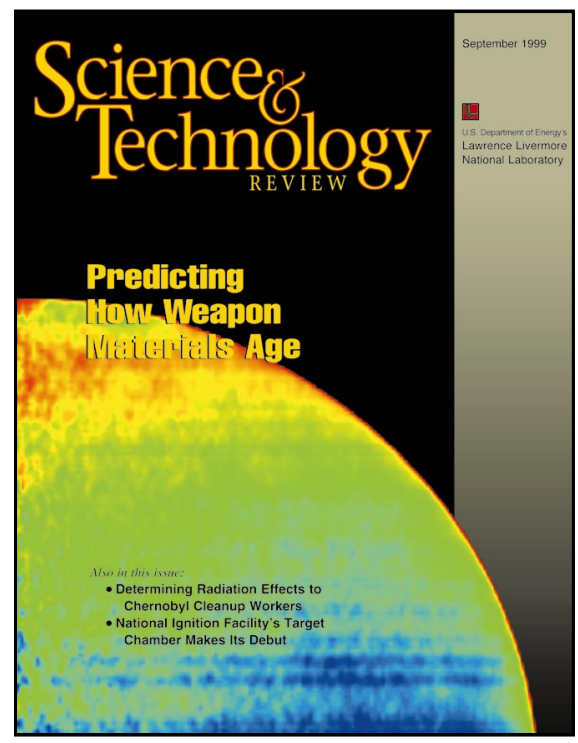

\section{About the Review}

Lawrence Livermore National Laboratory is operated by the University of California for the Department of Energy. At Livermore, we focus science and technology on assuring our nation's security. We also apply that expertise to solve other important national problems in energy, bioscience, and the environment. Science \& Technology Review is published 10 times a year to communicate, to a broad audience, the Laboratory's scientific and technological accomplishments in fulfilling its primary missions. The publication's goal is to help readers understand these accomplishments and appreciate their value to the individual citizen, the nation, and the world.

Please address any correspondence (including name and address changes) to $S \& T R$, Mail Stop L-664, Lawrence Livermore National Laboratory, P.O. Box 808, Livermore, California 94551, or telephone (925) 422-8961. Our electronic mail address is str-mail@1lnl.gov. $S \& T R$ is available on the World Wide Web at www.llnl.gov/str/.

(C) 1999. The Regents of the University of California. All rights reserved. This document has been authored by the Regents of the University of California under Contract No. W-7405-Eng-48 with the U.S. Government. To request permission to use any material contained in this document, please submit your request in writing to the Technical Information Department, Document Approval and Report Services, Lawrence Livermore National Laboratory, P.O. Box 808, Livermore, California 94551, or to our electronic mail address report-orders@1lnl.gov

This document was prepared as an account of work sponsored by an agency of the United States Government. Neither the United States Government nor the University of California nor any of their employees makes any warranty, expressed or implied, or assumes any legal liability or responsibility for the accuracy, completeness, or usefulness of any information, apparatus, product, or process disclosed, or represents that its use would not infringe privately owned rights. Reference herein to any specific commercial product, process, or service by trade name, trademark, manufacturer, or otherwise, does not necessarily constitute or imply its endorsement, recommendation, or favoring by the United States Government or the University of California. The views and opinions of authors expressed herein do not necessarily state or reflect those of the United States Government or the University of California and shall not be

used for advertising or product endorsement purposes.

Prepared by LLNL under contract No. W-7405-Eng-48 


\section{S\&TR Staff}

\section{SCIENTIFIC EDITOR}

David Eimerl

\section{MANAGING EDITOR}

Sam Hunter

\section{Publication Editor}

Dean Wheatcraft

\section{WRITERS}

Arnie Heller, Katie Walter, and Dean Wheatcraft

\section{Art Director and Designer}

George Kitrinos

\section{INTERNET DESIGNER}

Kitty Tinsley

\section{COMPOSITOR}

Louisa Cardoza

\section{Proofreader}

Carolin Middleton

$S \& T R$, a Director's Office publication, is produced by the Technical Information Department under the direction of the Office of Policy, Planning, and Special Studies.

$S \& T R$ is available on the World Wide Web at www.llnl.gov/str/.

\section{Science $_{8}$ Technology \\ Lawrence Livermore National Laboratory}

\section{The Laboratory in the News}

3 Commentary by Hal Graboske Life Performance of Complex Systems

Feature

4 A Better Picture of Aging Materials

Fundamental materials science and experiments on components of stockpiled weapons are coming together to produce models that predict the lifetimes of weapon materials.

\section{Research Highlights}

12 Researchers Determine Chernobyl Liquidators' Exposure

16 Target Chamber's Dedication Marks a Giant Milestone

20 Patents and Awards

\section{Abstract}

Printed in the United States of America

\section{Available from}

National Technical Information Service

U.S. Department of Commerce

5285 Port Royal Road

Springfield, Virginia 22161

\section{UCRL-52000-99-9}

Distribution Category UC-0

September 1999

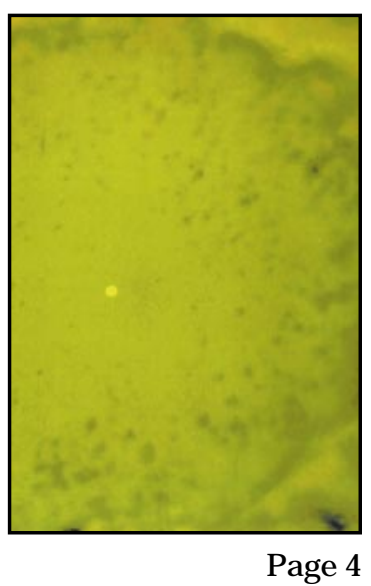

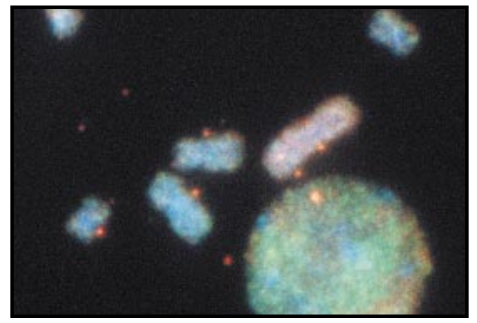

Page 12

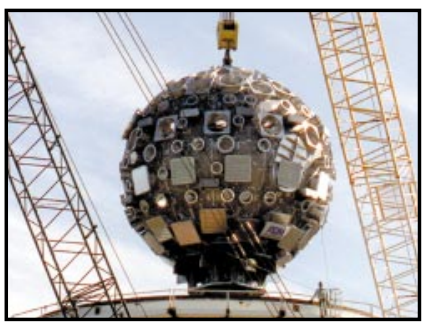

Page 16 


\section{Lab wins six R\&D 100 awards}

Livermore researchers turned in another strong showing in the annual R\&D 100 awards competition for top industrial inventions, winning six awards. Each year, $R \& D$ Magazine presents these awards to the top 100 industrial, high-technology inventions submitted to its competition for outstanding achievement in research and development.

Over the past three years, Laboratory scientists, engineers, and technicians have brought home a total of 20 R\&D 100 awards, and since 1978, they have won 81 of these prestigious awards. All told, U.S. Department of Energy laboratories won 40 of this year's 100 awards, 10 more than were garnered in 1998 by DOE research facilities.

The six Livermore inventions honored are:

- The Optical Modulator/Switch provides solutions to the high cost of modulating data onto a laser beam and switching signals from one data channel to another. This invention was developed in association with researchers from AlliedSignal Federal Manufacturing \& Technology and the University of Maryland at College Park.

- Gamma Watermarking is a revolutionary method of identifying and authenticating a range of material objects-from dinosaur bones to priceless objects of art to legal documents and contracts-with the same quality and legal incontrovertibility as DNA fingerprinting.

- The Diode-Pumped Solid-State Green Laser for Industrial Material Processing provides a cost-effective, higher-power replacement for lamp-pumped solid-state lasers and has applications in laser isotope separation and precision laser machining.

- The Solid-State Power Source for Advanced Accelerators and Industrial Applications enables accelerators to greatly increase the production of electron beams that in turn are used to produce bursts of $\mathrm{x}$ rays for examining the effects of aging on the nation's stockpiled nuclear weapons without underground testing. Researchers from Bechtel Nevada contributed to this invention.

- The Atomic Precision Multilayer Deposition System provides a faster, less expensive method for depositing multilayer thin films to precise, uniform atomic thickness over large flat or curved surfaces. It enables rapid development of all the convex and concave optics needed for extreme ultraviolet lithography.

- PEREGRINE, a radiation dose calculation system, tackles the problem of determining the proper radiation therapy dosage by using models based on fundamental physics principles. PEREGRINE calculates radiation therapy doses of the highest accuracy for cancer patients.

$S \& T R$ will devote its October issue to detailed reports on Lawrence Livermore's award-winning inventions and the teams that created them.

Contact: Karena McKinley (925) 423-9353 (mckinley3@IInl.gov).
Lab helps design Chernobyl robot

Department of Energy Deputy Secretary T. J. Glauthier recently dedicated a small but sturdy U.S.-made robot for Ukrainians to use in mapping the interior of the Chernobyl nuclear power plant, site of the 1986 disaster.

Dubbed Pioneer, the robot was designed by Lawrence Livermore and several other research agencies and was built by RedZone Robotics Inc. of Pittsburgh, Pennsylvania. Less than 1.2 meters tall and resembling a miniature bulldozer, it is expected to endure about two years within the extremely radioactive remains of Chernobyl rather than the seven minutes its predecessor lasted before melting and malfunctioning.

Maynard Holliday, the Livermore robotics expert who served as the Pioneer project manager through December 1998, noted, "This project is an outgrowth of our cooperation with the states of the former Soviet Union. This is just one small step in giving the Ukrainians state-of-the-art tools to understand what they're dealing with."

Pioneer is designed to withstand thousands of times more radiation exposure than humans can tolerate. It could be sent inside Chernobyl within a few months, after Ukrainian scientists are fully trained in its use and after more simulations are conducted in terrain similar to that in Chernobyl's rubblefilled interior.

Contact: Maynard Holliday (925) 422-3646 (holliday1@Ilnl.gov).

\section{Teller chair endowed at UC Davis}

Dr. Edward Teller, one of the founders of Lawrence Livermore National Laboratory and perhaps its most famous employee, was recognized in mid-June with yet another in a long list of honors and awards. A \$1-million grant from the Fannie and John Hertz Foundation endowed the Edward Teller Chair in the University of California at Davis's Department of Applied Science.

Teller founded the Department of Applied Science in 1963 and served as its chairman until 1966. It is located adjacent to Lawrence Livermore and is a prime example of Teller's lifelong interest in science education. Students who participate in the department must submit to a rigorous entry interview and combine academic studies in applied science with handson work at the Laboratory. The faculty includes staff from the UC Davis Department of Engineering and scientists and engineers employed at Lawrence Livermore.

During a news conference following the announcement of the endowment, Teller was asked to put the endowment in the perspective of the many honors he has received. Teller replied, "There's absolutely no award, there's nothing in the world that could be as valuable to me as a plan to better educate our next generation of applied scientists."

Contact: LLNL Public Affairs Office (925) 422-4599

(garberson1@IInl.gov). 


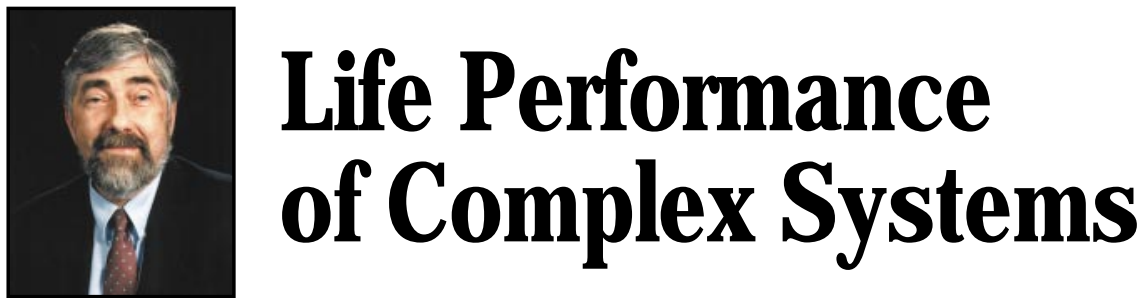

T $\mathrm{HE}$ world today is using increasingly complex systems and taking them for granted. For the scientists and engineers who design and maintain them, two classes of systems present particular challenges: those that operate under extremely stressful conditions and those that are required to operate for extremely long periods of time. Jet aircraft, spacecraft, satellites, and nuclear reactors encounter enormous stresses. Aircraft and spacecraft also often continue to operate for longer than their designed lifetime. We at Lawrence Livermore have been mandated under the Department of Energy's Stockpile Stewardship Program to extend the life of weapons in our nuclear arsenal well beyond the lifetime for which they were designed. We are also collaborating on the design of the Yucca Mountain nuclear waste repository, which may be required to operate for 10,000 years.

For all of these systems, the penalty for failure is high. Injury, death, even major devastation of our planet could result from errors made during design, construction, operation, or maintenance. Yet to a certain extent, these extraordinarily complex and long-lived systems are beyond testing because we cannot be certain whether we have tested them well enough or long enough. Nevertheless, at Livermore, we subject weapon parts and components to rigorous conditions for extended periods before the weapon is assembled and later during its life in the stockpile. We understand that the stakes are high and that high standards are essential during all phases of the system's life.

Nuclear weapons typically contain specially developed and unusual materials. Engineered to meet a specific need that conventional materials could not, these new materials have a limited track record. Researchers have scant information about their evolution and about how the many materials will react with one another sealed in a nuclear weapon or in a waste repository. Incompatibilities that are not apparent over a short time may take on great significance over long periods.

So how do we, as responsible stewards of our nuclear arsenal and nuclear waste, respond to these challenges? For complex systems with long lifetimes, our approach comprises four integrated elements: prediction, testing, surveillance, and modification.

As described in "A Better Picture of Aging Materials," the article beginning on p. 4, we are striving to develop improved behavioral and computational models of system performance and effective life expectancy using the best scientific and engineering knowledge and the world's fastest supercomputers. Only with the powerful computers available to us through the DOE's Accelerated Strategic Computing Initiative can we be confident in the predictions for complex systems.

Experimental validation is typically performed initially to determine material properties, again to operationally test components and subassemblies, and finally to test the performance of an entire subsystem or system. But for nuclear weapons, we cannot perform the third phase of testing in its entirety. Computational modeling must of necessity replace full performance testing, previously accomplished through nuclear experiments. This is where the evolution of validated age-aware material models will become key to assessing the life performance of complex systems.

Surveillance incorporates an array of diagnostic techniques for monitoring the nuclear stockpile or the nuclear repository Because we no longer monitor performance with nuclear testing, our surveillance of the many materials that make up the system has taken on new importance.

Data from surveillance and all material and operational tests are essential for validating our computational models and identifying where models need to be changed and limited resources should be focused. Finally, the predictive models notify us when modifications are needed in a weapon system before its performance is reduced.

This integrated approach to complex systems is in itself complex. It involves many disciplines and can be handled effectively only by an organization with the depth and breadth of experience of a DOE laboratory such as Lawrence Livermore.

Hal Graboske is Associate Director, Chemistry and Materials Science. 


\section{Our nuclear stockpile is getting older. Livermore scientists are collecting the}

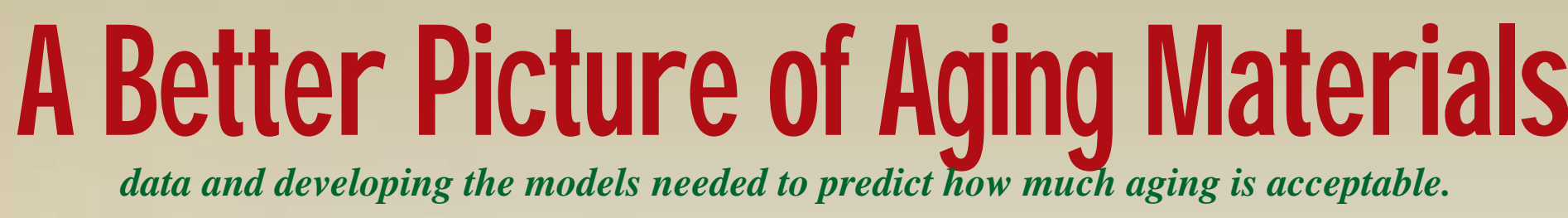

$\mathrm{N}$ UCLEAR weapons are complex systems made of many different materials and interconnecting components. The materials may interact with air, moisture, and environmental hazards during manufacture, shipping, storage, and assembly as well as with each other once they have been enclosed in the weapon. They may weaken, harden, corrode, or even fail. These changes in properties, whether chemical, physical, or mechanical, are often lumped together under the label "aging."

The shelf life of a nuclear weapon was not a major issue until the early 1990s when the U.S. ceased to develop and test nuclear weapons. Before that, new weapons featuring the latest technology were regularly designed and built. When a new weapon entered the stockpile, an older one was generally retired. Now, there are no new weapons, and existing weapons are expected to remain operational for many decadesto perform exactly as designed if they must ever be used.

The Department of Energy's Stockpile Stewardship Program has many facets, one of which is to analyze the aging processes of the materials used in nuclear weapons, such as high explosives, uranium, plutonium, organic materials, and polymers. This analysis builds on work that materials scientists at Lawrence Livermore have been doing since the inception of the Laboratory. In the past, they studied how various materials aged and interacted under stockpile conditions to provide guidance on the selection and use of the best available materials for Livermore's new weapons. Today, the mandate for materials scientists is more complex: to predict the lifetime of key weapon materials and to develop "age-aware" material models for use in codes that predict the lifetime of the overall weapon system.

Livermore chemist James LeMay is one of the coordinators assigned to this challenging set of activities. He and his colleagues are focusing primarily on the aging of the many organic materials used in a weapon. They are also examining the aging of high explosives and the interactions (compatibility) of the many materials in a nuclear weapon.

\section{Data for Predictions}

LeMay notes, "True scientific prediction, as opposed to a statistical projection, of how weapon materials age and interact with one another over time is difficult. Accurate predictions require excellent data, sophisticated models, and powerful, modern computers."

The data come from several sources. One is controlled laboratory experiments on weapon materials. They determine the properties of the materials before they begin to age, what environmental forces act upon them while they are enclosed in the weapon, and how those forces change the properties that are relevant to the performance of the system. In other words, a major focus of the work is on the fundamental science of materials.

Another source of data is the detailed characterization of components taken from the stockpile to determine how their relevant properties have changed (Figure 1). These measurements supplement DOE's Core Surveillance Program to verify the safety and reliability of U.S. nuclear weapons. Under core surveillance, weapons are removed from the stockpile on a regular basis and disassembled. Components are tested to assure that they operate as they did when the weapon was assembled. Under the newer Enhanced Surveillance Program, more detailed and fundamental experiments seek out previously unknown aging mechanisms that may affect a material's lifetime and allow scientists to extrapolate future aging trends from changes that have already occurred.

With accurate predictive models, researchers should be able to reduce the required number of system-level evaluations, which are expensive. Robust models would reflect what chemical or physical alterations in a material are under way and at what point component or weapon performance is affected. Surveillance could then be directed to look for predicted changes and to find previously unanticipated ones, thus providing a means for continual improvement and validation of predictive models. "We've got a long way to go," says LeMay, "but we have made considerable progress."

\section{How Much Change Is OK?}

Some materials in a nuclear weapon are designed to be marginally unstable. 


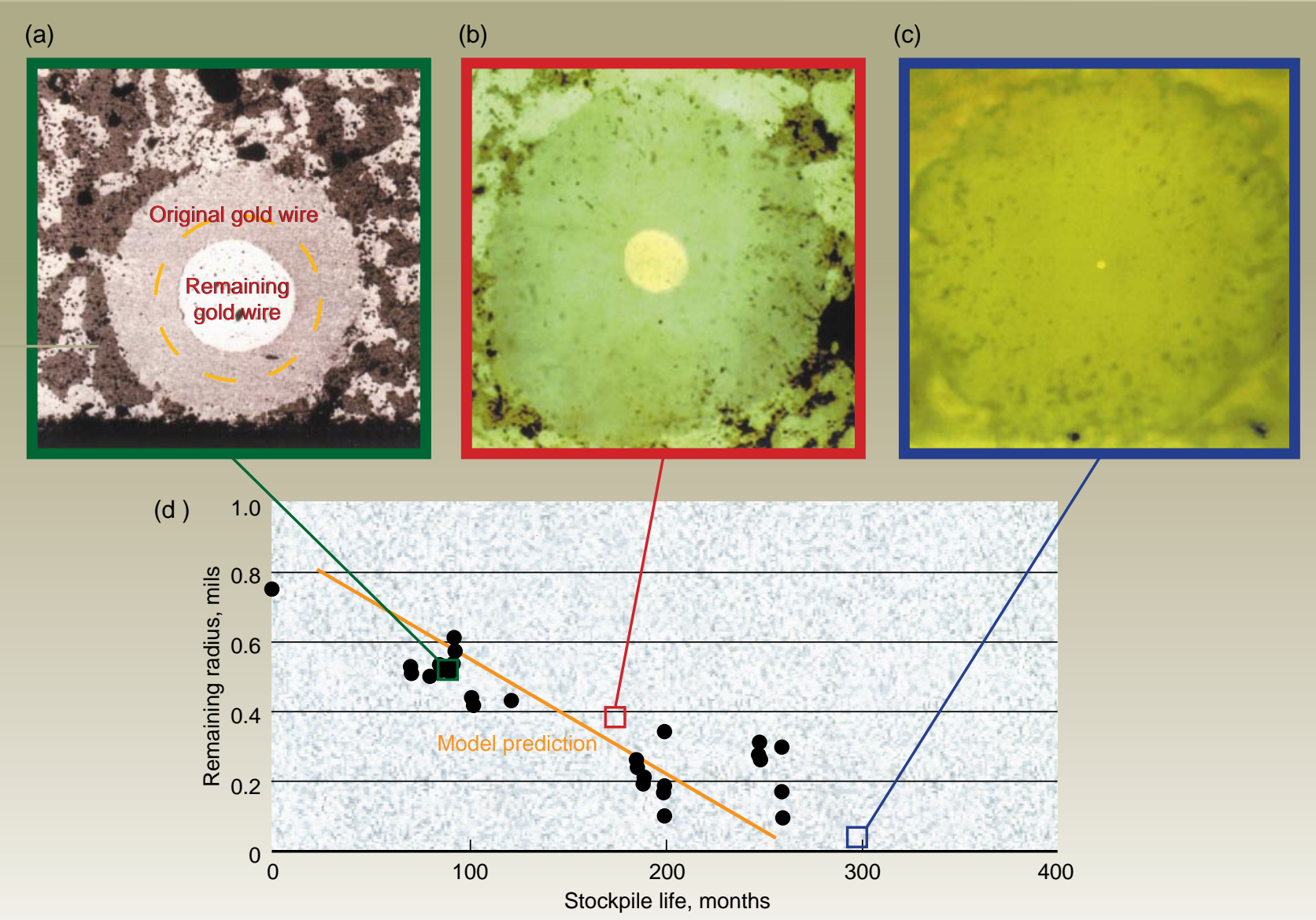

Figure 1. A multidisciplinary weapons program team at Livermore has studied the aging of the gold detonator bridgewires in previously stockpiled weapons. (a), (b), and (c) Cross sections of detonators removed from a previously stockpiled weapon. They illustrate the conversion of the bridgewire from gold to gold indide over the course of about 25 years. Gold indide has mechanical and electrical properties quite different from those of gold. (d) The predictive model in the graph indicates that these gold bridgewires corrode dramatically as they age. Actual aging data match the predictive model extremely well.

The high explosives used for initiation must be somewhat sensitive or they will not detonate. Radioactivity adds another dimension of instability. Even those parts that are theoretically stable can present difficulties. A bit of oil may be left on a part during manufacture. A trace of water vapor might appear in the system, causing corrosion. A seal might leak and admit oxygen and water. Materials that appeared to be pure at the time of manufacture may prove to be incompatible and react with one another. In all cases, these aging processes and interactions are extremely slow.
When a weapon is assembled, its array of components is not in thermodynamic equilibrium. Unfortunately, it is a basic law of nature that all of the parts in a closed system will strive for thermodynamic equilibrium. They will change and perhaps degrade by exchanging energy until equilibrium is achieved. In a nuclear weapon, that process would take a long time, but some components change faster than others and can cause unacceptable aging.

At some point in the degradation process-probably long before global thermodynamic equilibrium is achieved-the weapon will cease to be viable. One or more of its parts may have changed just enough or even failed such that the weapon no longer performs as required. An assumption of Livermore's materials aging studies is that there is a slightly earlier point where considerable aging has occurred and yet the weapon still operates as designed. LeMay likens it to an older automobile that still runs well but whose brakes are rather worn, whose tires are a bit flat, and whose engine does not turn over quite as quickly in the morning. The important questions are: Where is that point for a nuclear 
weapon? How much change is $\mathrm{OK}$ for the individual materials in the weapon?

\section{The Materials at Hand}

Livermore-designed nuclear weapons that reside in the stockpile have various configurations. But they generally incorporate plutonium, uranium, high explosives, plastics, adhesives, foams, and other materials that together make the weapon generate its designed yield.

To date, many changes related to aging and to incompatibilities between weapon materials have been observed. In the six high explosives used in various weapons, changes include swelling, plasticizer migration, binder degradation, mechanical property degradation, adhesive bond rupture, and incompatibilities. In addition, changes related to load retention and compression were found in the polymer foam cushions that provide padding between various weapon components.

Uranium, plutonium, lithium, and even gold exhibit surface corrosion. Several materials are affected by radiation from uranium and plutonium. Researchers also found incomplete curing, depolymerization, and hydrogen outgassing in some silicone

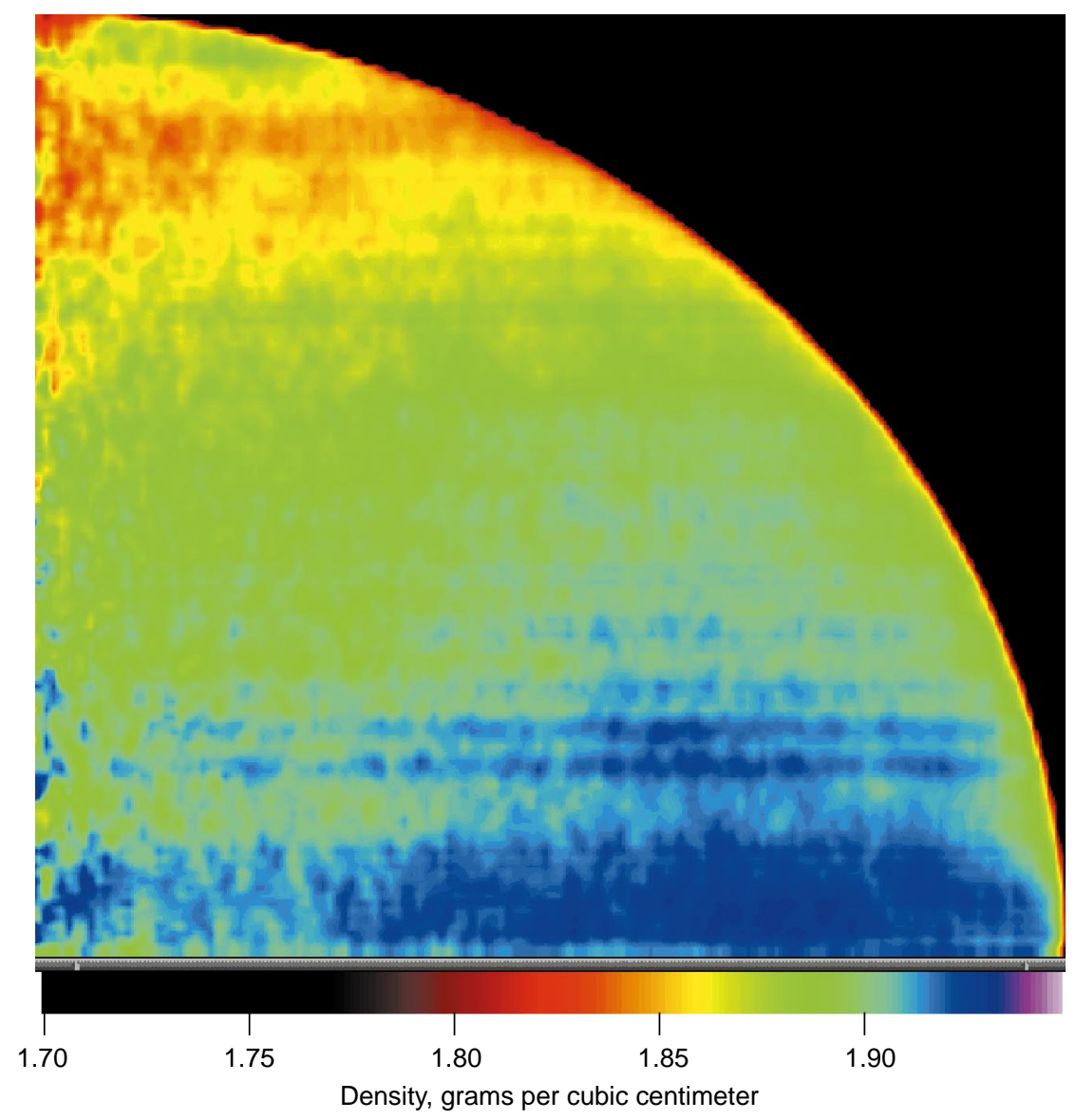

Figure 2. Using x-ray tomography, Livermore scientists led by Clint Logan have calculated the density distribution within a booster pellet made of ultrafine insensitive high-explosive powder (TATB). The pellet has a radius of 1.9 centimeters and weighs 26.1 grams.

compounds. In plastic parts, some polycarbonate material was degraded by ammonia gas emitted from a nearby component. An undesirably strong adhesion has developed between some plastic components. Some adhesives have incompletely cured, some are outgassing, and some bonds have weakened.

Organic materials are a particular concern. By their very nature, they can be less stable than many other materials. They have weaker bonds and tend to be reactive. They also are more readily damaged by the radiation that emanates from uranium and plutonium. Nevertheless, organics are an essential part of a weapon. Some serve chemical functions such as hydrogen "getters," which absorb damaging hydrogen in a weapon's hermetically sealed environment.

Other organics (such as silicone stress cushions, adhesives, and coatings) fill gaps, transmit loads, and mitigate vibration and shock, allowing a weapon to survive what is known as the stockpile-to-target sequence (STS). A weapon sitting in the stockpile encounters few traumas, but during the STS, it must endure transport on a truck, temperature changes during storage, and perhaps ultimately a launch and flight from under the wing of a plane, from a submarine, or from a land-based missile silo.

For experiments that examine everything from bulk materials to individual atoms, Livermore scientists are using a unique collection of tools to examine and test the surfaces and structure of the many materials that make up a weapon. Some of these tools were developed at Livermore. Others were developed elsewhere but modified at Livermore for use in the stewardship of the U.S. nuclear arsenal.

\section{An Explosive Issue}

Many years ago, Livermore opted to use insensitive high explosives in its 
nuclear weapons for greater safety.

An insensitive high-explosive component dropped during assembly or disassembly should not harm personnel, and a weapon that accidentally falls from a truck or even from an airplane should not detonate. But scientists are concerned that these high explosives might lose some of their safety advantage as they age. For example, voids in high explosives are necessary to drive the detonation wave. But if voids increase in size as the explosive ages, the explosive may become somewhat less safe. High explosives are therefore a primary focus of Livermore's work on aging weapons, and many experiments have been performed over the years.

Because the insensitive high explosive LX-17 is used in three of the four Livermore-designed weapons in the enduring stockpile, its reliability is paramount. Physicist Richard Howell and his colleagues under the leadership of George Overturf have conducted a number of experiments on LX-17 using positron-annihilation lifetime spectroscopy to search for interior voids and open volumes as small as several atomic bond lengths in diameter. (See $S \& T R$, December 1998, pp. 13-17.) Overturf's team has used this method to measure changes in the microscopic, open-volume voids of LX-17's constituents, including the high-explosive powder TATB and its polymeric binder. His goal is to observe changes that occur as a result of temperature variations and environmental stresses during stockpile life.

Another experiment produced the first look at the density of a booster pellet (Figure 2). X-ray computed tomography was used to examine the density of a hemisphere of ultrafine high-explosive powder with no binder. This new tomographic technique is being used to correlate observed density variations with the material's age and its performance with measured density variations.

\section{Extracting Gases}

Over a period of years and at elevated temperatures, the many organic materials in a nuclear weapon eventually produce gases at detectable levels. There are two types of outgassing: the release of gases in the assembly room that become trapped in weapon cracks and crevices or dissolved in its organic components and the release of gases inside the weapon that are produced by chemical aging reactions, material interactions, or radiation. By either route, organic materials release compounds that can corrode metals and/or interact with and degrade other materials and components in the system. In general, outgassing signals the interaction and possible decomposition of materials in the warhead.

LeMay notes that just as surveillance scientists and engineers use nondestructive tools to assess changes in weapons without disassembling them, so do compatibility and aging scientists take advantage of nondestructive chemical tools to assess changes in weapon chemistry and compatibility.

One such tool is solid-phase microextraction (SPME, or "speemee"), which Livermore chemist David Chambers has adapted to examine gases for stockpile surveillance. A syringe needle containing a tiny, specially coated fiber is inserted into the headspace of a weapon to sample gases (Figure 3). Gas chromatography and mass spectrometry of the tiny sample then supply data on the contents of the weapon atmosphere. Unlike most other sampling techniques, SPME can deliver high-quality samples of the

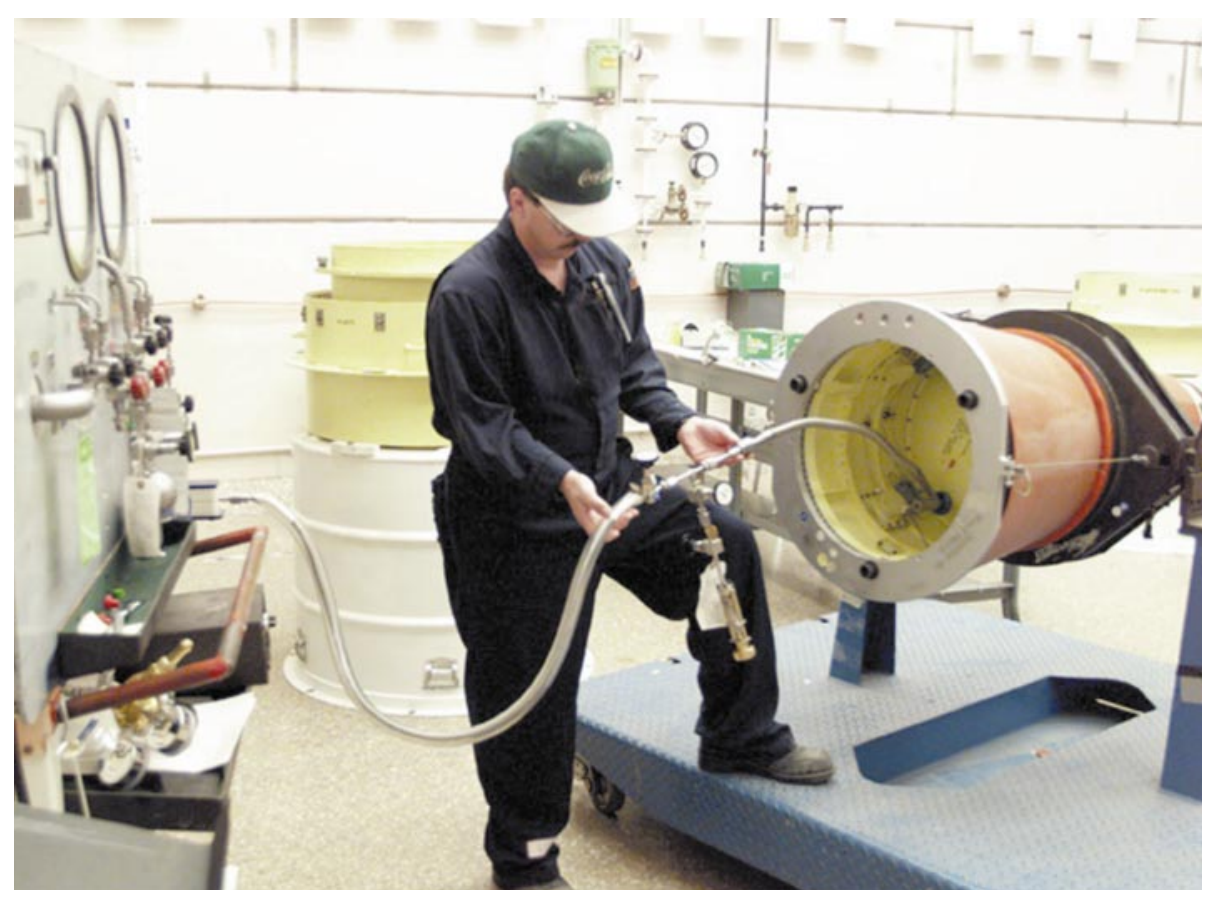

Figure 3. A technician uses an early prototype of the solid-phase microextractor (the device between his hands) to take samples of gases produced by organic materials in a weapon's headspace. Analysis of the samples provides indications of material aging. 
weapon's atmosphere to the gas chromatography port with little loss or dilution.

Livermore is the first laboratory to use SPME, a nondestructive technique, to examine weapon gases. With SPME, scientists can obtain an integrated chemical analysis of a weapon's interior environment, identifying potential material incompatibilities, identifying and monitoring aging indicators, and screening for defects such as incompletely cured adhesive and organic residues left over from assembly.

Chambers notes that with SPME, otherwise undetectable volatile gases are now detectable. For example, SPME was the first experimental method to reveal relatively large amounts of toluene in LX-17. Toluene is a solvent used in the synthesis of TATB, which is the primary ingredient in LX-17. After production, toluene remains trapped within TATB's crystalline structure. Experiments indicate that heating alone does not effectively liberate the toluene unless the LX-17 has been mechanically stressed. One experiment exposed TATB powder to ultrasonic energy and found a 500-fold increase in the level of toluene outgassing. Chambers believes that toluene levels can be monitored to determine the chemistry and stressloading history of the high explosive.

\section{Cushioning the Warhead}

Cellular silicone stress cushions fill gaps between components, compensate for manufacturing tolerances of adjacent components, allow for thermal expansion of components and age-induced swelling of high explosives, and provide thermal insulation. For the cushions to perform these jobs successfully, they must exert a specific range of compressive forces at predetermined maximum and minimum gaps. Because the cushions fill gaps for the life of the weapon, the long-term stress behavior of the cushion under load in the chemical and radiation environment of a weapon is an ongoing concern.

LeMay has been examining aging in cellular silicone using a form of $\mathrm{x}$-ray tomography developed at Livermore by materials scientist John Kinney. This technique reveals for the first time the internal structure of cushions under compression (Figure 4). It is now possible to see how some cells fold into one another to form "cups" and that cell wall "hinges" spring back after the load is removed. Some cells move to fill

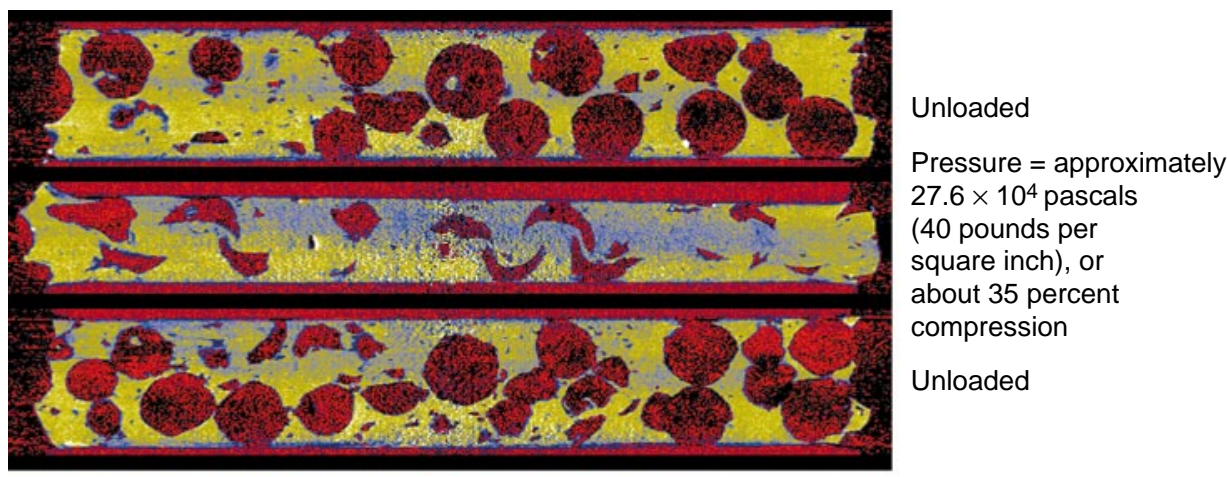

Figure 4. X-ray tomography is revealing for the first time the internal structure of cellular silicone cushions under compression. Note that some cells fold into one another, resulting in a structural change should the adjacent cell walls adhere to one another over time.

adjacent cells under compression. X-ray tomographic data can also be manipulated to show the shape of the cushions' pores. These images can be used, for example, to determine under what range of loads the pores remain interconnected, thus allowing gases and radiation to percolate through.

Because radiation from adjacent components is constantly bombarding the cushions and apparently percolating through them, LeMay and others are attempting to determine the damage it may be causing. Only preliminary data are available, because the researchers are still developing experimental tools that are sensitive enough to characterize radiation's effects.

Another Livermore chemist, Mehdi Balooch, used temperature-programmed desorption to study gases desorbed from silicone cushions. He found that at temperatures up to 500 kelvins, water desorbed at 100 micrograms per gram of silicone, with considerably less desorption of hydrogen, carbon monoxide, and carbon dioxide. The real concern was water, because silica, which makes up about 25 percent of the cushions, tends to adsorb water. Outgassing water vapor in a closed environment can migrate to other parts in the warhead and cause corrosion. This experiment-to further understand a fundamental property of a commonly used material in a weapon-demonstrates the need for basic science in the study of aging weapon materials.

\section{Hydrogen: The Enemy Within}

Balooch is also working with Wigbert Siekhaus to study the aging processes of uranium and lithium hydride. Specifically, they are studying the effects of such gases as water vapor and hydrogen on the surfaces of these materials: what the reactions are, what products are formed, and how the reactions depend on temperature, gas pressure, and the 
surface details. They have used atomic-force microscopy to get a close-up look at growths on the surface, modulated molecular-beam mass spectrometry to determine the gaseous reaction products and the rate of reactions, and temperatureprogrammed desorption to measure the quantity of adsorbed gases.

"Hydrogen is a major enemy of a weapon," according Balooch. It is generated in a weapon from several sources and attacks many components. Hydrogen is particularly damaging to uranium, reducing its capabilities. If a uranium surface is even slightly oxidized (a process that happens easily and quickly), it will adsorb hydrogen, prompting the growth of a form of corrosion known as hydride pitting along the uranium's grain boundaries (Figure 5). Scientists have had empirical evidence for the hydriding reaction for some time. But the reaction mechanism had never been studied in detail, and a general mechanism had not been identified.

A few years ago, Livermore researchers demonstrated the fundamental properties of the interaction of hydrogen and water vapor with clean uranium at room temperature and above. They measured the initial sticking probability (low for clean uranium), hydride formation probabilities, and desorption kinetics for hydrogen and water vapor.

A more recent experiment examined the interaction of hydrogen with uranium in the presence of impurities designed to mimic conditions in real systems. Tiny platinum particles measuring just 1 nanometer were deposited on a uranium surface. Platinum was used because it breaks hydrogen bonds to produce atomic hydrogen, hydrogen's most reactive form. When the uranium was exposed to hydrogen, hydrides formed in the vicinity of platinum clusters, expanding nonlinearly over time. Other impurities commonly found in uranium may also strongly influence hydriding reactions.
A major source of hydrogen in some nuclear devices is lithium hydride. The reaction of even trace amounts of water with lithium hydride generates hydrogen. The team has been using modulated
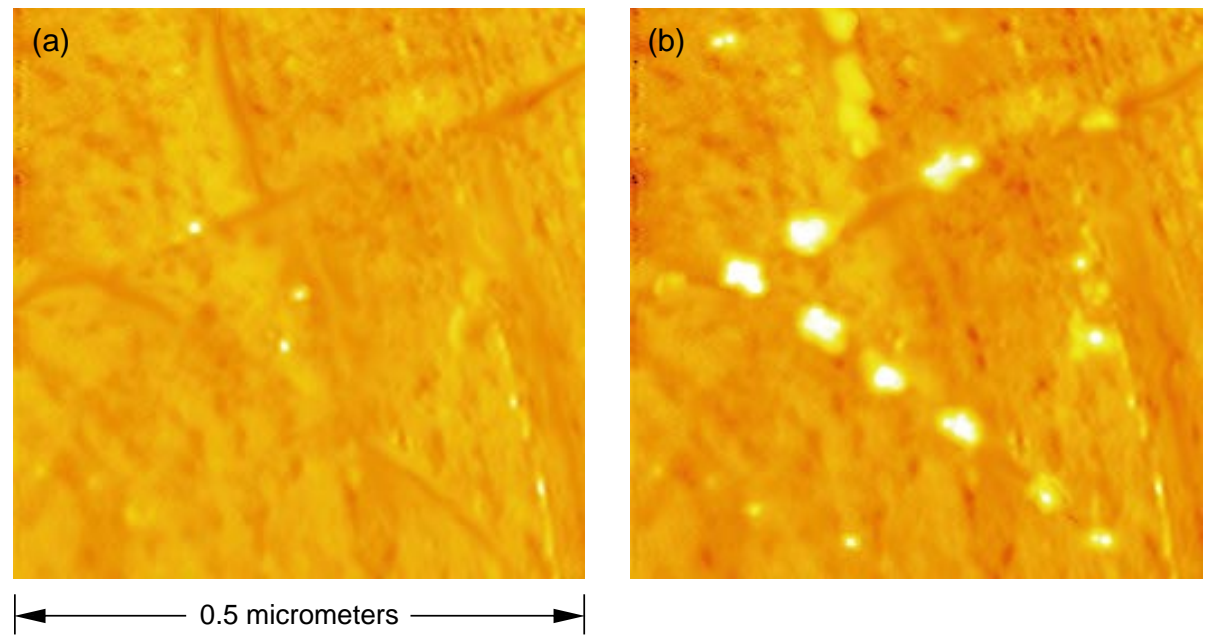

Figure 5. Atomic-force microscopy shows (a) uranium before hydriding takes place and (b) the formation of uranium hydride along grain boundaries, or hydride pitting.

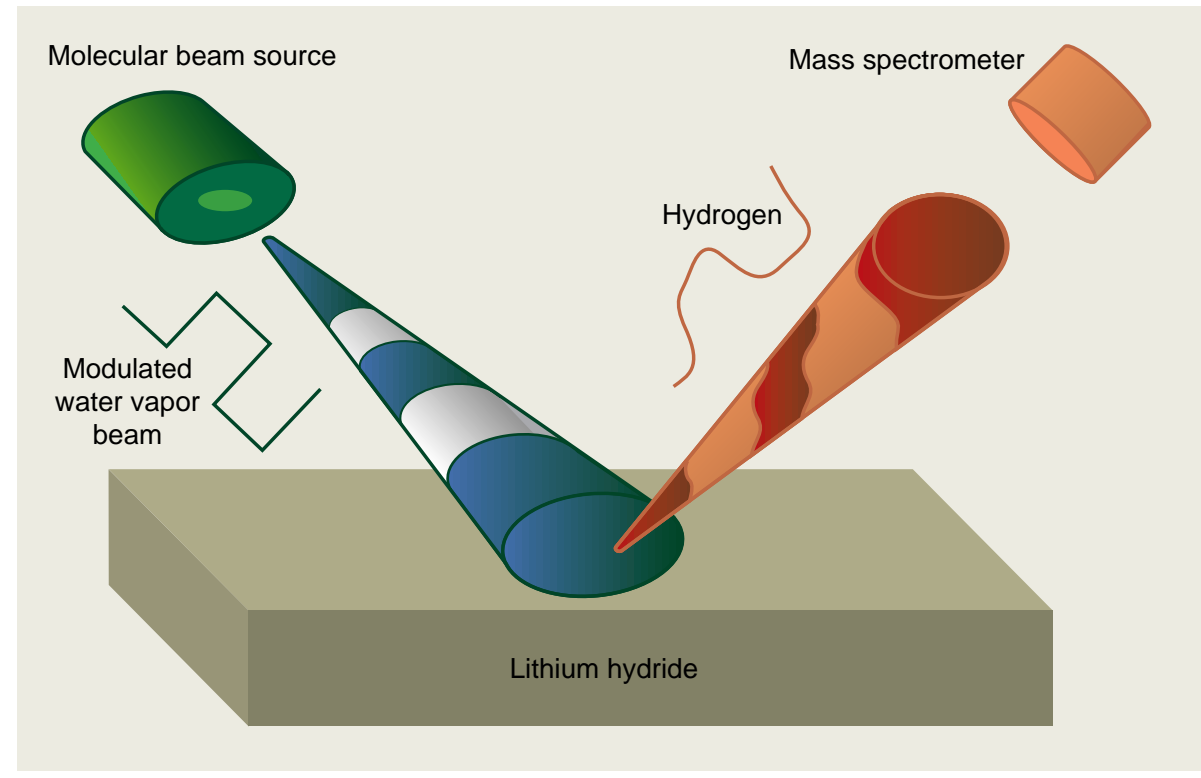

Figure 6. This schematic shows a modulated molecular-beam mass spectrometer being used to study the effects of water vapor on lithium hydride. The beam of water vapor directed at the lithium hydride is turned on and off at brief, regular intervals, as shown in the square pattern of the incoming beam. The outgoing beam of molecular hydrogen has a different shape, indicating a brief residence time in the lithium hydride. 
molecular beam have different shapes, indicating a brief resident time in the lithium hydride. With these experiments, the team will be able to obtain basic information about lithium hydride and the reactions under way, including the sticking probability, reaction probability, elementary surface reaction steps, and diffusion rates.

Livermore is the only institution in the world using modulated molecularbeam techniques. Balooch, Siekhaus, and Alex Hamza developed the method about 20 years ago while they were at other institutions. According to Balooch, modulated molecular-beam experiments give the best chemical kinetic information.

\section{Putting It All Together}

Siekhaus notes that DOE weapons laboratories have detailed models for the multitude of reactions that take place immediately after a weapon is detonated but nothing comparable to describe the life of a weapon before detonation. With the relatively short shelf life that weapons used to have, such models were not necessary. But today they are.

Several years ago, chemist Dan Calef began developing a predictive model for one part of a nuclear device using data that the experimentalists have accumulated on lithium, uranium, gases, and other materials. As LeMay noted, excellent data are important to create such models. In a system as small and tight as a nuclear device, trace amounts and slow reactions matter. What seems to be a small issue can become magnified quickly.

According to Calef, "Until recently, decisions about lifetimes tended to be based on expert opinion and experience. Our goal is to make these decisions from a science-based standpoint."

His first task is to model the transport of gases around the system. The originally designed geometry of the weapon system and all available experimental data are going into ALE3D, a Livermore hydrodynamic code. He will then examine all the chemical reactions that occur over time and how these processes change the designed geometry. Figure 7 shows a structural change that results from mass diffusion.

Calef is particularly interested in the small details in the system, such as pores and gaps between components. It is in those minute spaces that such critical activities as diffusion and destructive surface chemistry take place. With this close-up view, he can

Figure 7. Mass diffusion and structural distortion as shown in an ALE 3D model. In this calculation, (a) a solid object reacts with a gas diffusing through a gap. (b) The reacted solid has a lower density and expands.

(a) Gas diffuses through the gap
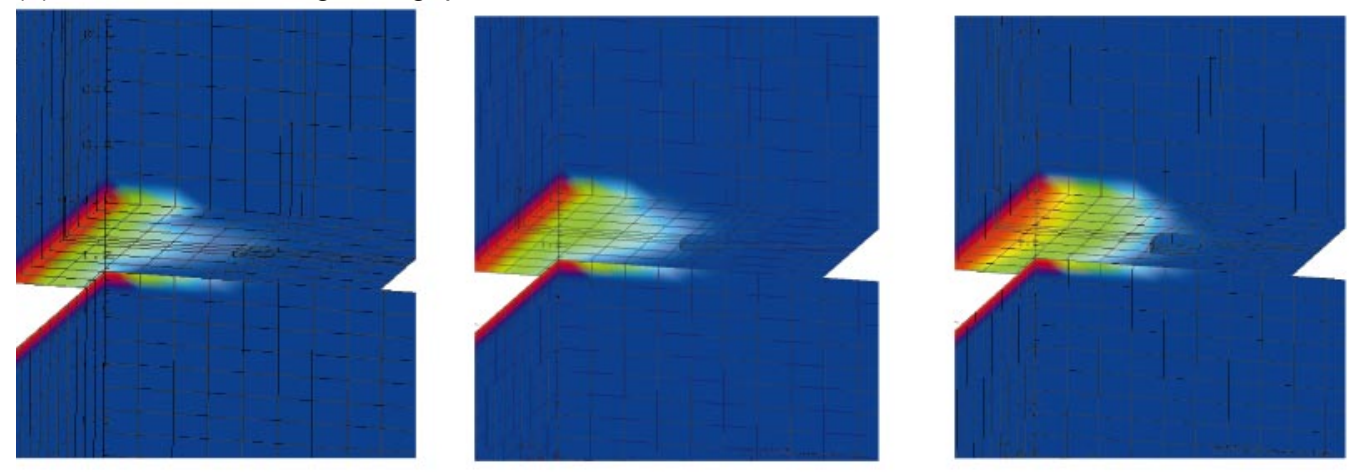

(b) Core material in the object reacts and expands
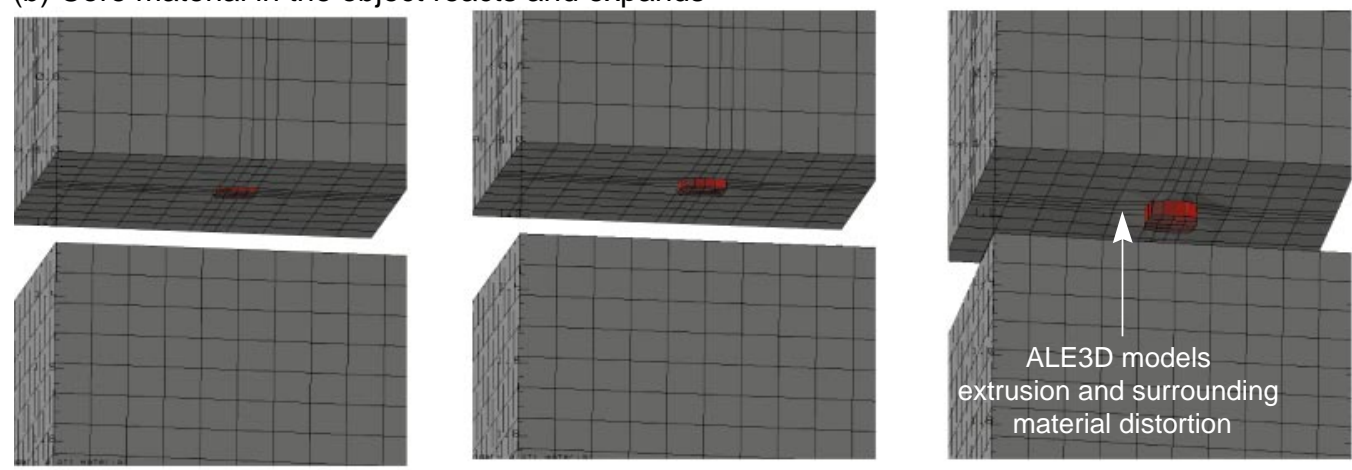
determine where problem areas might be. From there, he will define any lifelimiting components and determine the lifetime of the system.

Livermore weapon models already contain considerable detail, but the detail is of idealized materials. When the models are based on data from actual constituent materials and real chemical reactions, they will be much more useful. They can be tweaked to show what effect temperature changes, shock, vibration, and other influences have on a weapon. Identifying weak points for further experimentation can help to prioritize future research and development activities. Models could also help to identify which parts need to be replaced and when.

LeMay notes that his group and others at Livermore must continually refine their approach to characterizing and modeling the aging of Livermore's weapon materials. As with any modeling program, there is a strong dynamic between predictive efforts and continued experimentation. Even with the most powerful computers, modeling needs validation from experimental results in an ongoing, iterative process that constantly refines modeling results and methods.

LeMay and his colleagues will constantly be integrating their improved understanding of the aging process into weapon codes so that changes at the system level can be effectively assessed. LeMay concludes that the goal of science-based stockpile stewardshipmaintaining high confidence in the safety and reliability of Livermore's weapons without nuclear testingrequires constant vigilance.

- Katie Walter

Key Words: ALE3D, core surveillance, enhanced surveillance, materials science, modeling, modulated molecular-beam spectroscopy, positron-annihilation lifetime spectroscopy, solid-phase microextraction (SPME), surface chemistry, $x$-ray tomography.

For further information contact

J ames LeMay (925) 423-3599

(lemay1@IInl.gov).

\section{About the Scientist}

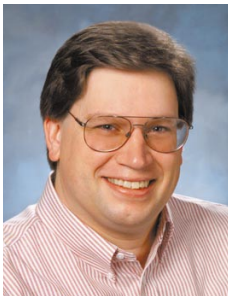

JAMES LEMAY received his B.S. in chemistry in 1980 and his Ph.D. in polymer science in 1984 , both from the University of Akron. He began working at Livermore in 1984. In 1991, he became Livermore's lead scientist for material compatibility issues. He has supported the W89 and W87 weapon programs, dismantlement of the W48 and W79 weapons, stockpile storage issues, and core surveillance activities. He is currently a program element leader for weapon materials compatibility and aging in the Chemistry and Materials Science Directorate and is a research and development focus area leader in the Enhanced Surveillance Program. In 1998, he received a Department of Energy Nuclear Weapons Program award for technical excellence in weapon materials. 


\section{Researchers Determine Chernobyl Liquidators' Exposure}

$\mathrm{O}$ N April 26, 1986, an accident at the Chernobyl nuclear reactor in the former Soviet Union released an enormous number of fission products into the atmosphere and over a large portion of the planet. With about 100 million curies released in the 10 days following the initial explosion, the accident was the largest single nonmilitary release of radioactivity in history - and one of the largest environmental disasters ever.

During the first year after the accident, about 25,000 people, mainly Soviet Army troops, were dispatched to the site to clean up the accident. These so-called liquidators were estimated to have received doses of up to 70 centigrays (a gray is the international unit for measuring absorbed ionizing radiation and is equivalent to 100 rads, or 1 joule per kilogram). In the following three years, another half-million people assisted the effort and are estimated to have received lower doses (about 10 to 25 centigrays).

The tasks performed by liquidators included shoveling core material off the roof of the undamaged part of the building, operating heavy equipment to contain contaminated soil, and building a concrete sarcophagus around the destroyed reactor. Depending upon the intensity of radiation exposure associated with their assigned task, most liquidators received radiation exposures over a period of at least several days, and in some cases over many weeks.

Lawrence Livermore biomedical scientists began studying the Chernobyl accident almost as soon as it occurred as part of a Department of Energy effort to help assess the accident's biological effects. The Livermore assistance, which continues today, takes advantage of the Laboratory's longstanding expertise in evaluating human exposures to ionizing radiation and determining their health risks. Livermore scientists have forged numerous and often close scientific relationships with their Russian and Ukrainian counterparts that endure today in collaborations, mutual assistance, informal communications, and visits.

\section{Techniques to Monitor Damage}

Lawrence Livermore studies on Chernobyl liquidators have focused on three techniques - two of them developed at Livermore in the 1980s - that are in wide use today to monitor genetic damage in people. The techniques are called biodosimeters because they measure changes in cells to infer the biological consequences of the "dose," or energy deposited in human tissue from ionizing radiation. (In contrast, a standard dosimeter uses a piece of sensitive film that responds proportionally to ionizing radiation.)

The glycophorin A (GPA) assay was first used to study Chernobyl liquidators who demonstrated immediate symptoms known as acute radiation sickness. Within days of the accident, a Livermore group (at that time led by Ron Jensen, now at the University of California at San Francisco) began receiving blood samples from people who received high exposures. The evaluation by Livermore's Richard Langlois found that the response of GPA to high doses of radiation was similar for A-bomb survivors and Chernobyl liquidators. The investigators also found that age and smoking had little effect on the frequency of the GPA null mutants.

The GPA assay measures the number of red blood cells that have a change in the $\mathrm{M}$ or $\mathrm{N}$ form of the GPA gene. For people whose cells have both forms of the gene, damage to the $\mathrm{M}$ form of the gene, for example, can result in a "null" mutation. In such a case, all descendants of that cell fail to make the M protein. Using flow cytometry and cells stained with color-coded antibodies specific to the $\mathrm{M}$ and $\mathrm{N}$ forms, scientists can study millions of red blood cells from a small blood sample in a few minutes without the need for cell culturing. (See August 1987 Energy \& Technology Review, "A New Assay for Human Somatic Mutations," pp. 21-26, and April/May 1992 Energy \& Technology Review, "The Glycophorin-A Assay: A Ten-Year Retrospective," pp. 1-18.)

The second technique measures the frequency of mutations of the hypoxanthine phosphoribosyltransferase (HPRT) gene in lymphocytes. This assay was not invented at Livermore, but Laboratory researchers have greatly expanded understanding of the assay's ability to detect DNA damage from ionizing radiation. Livermore biomedical scientist Irene Jones performed work in the 1980s using mice to test the assay. She also developed a database on healthy people to serve as a baseline for the frequency and molecular nature of HPRT mutations. 


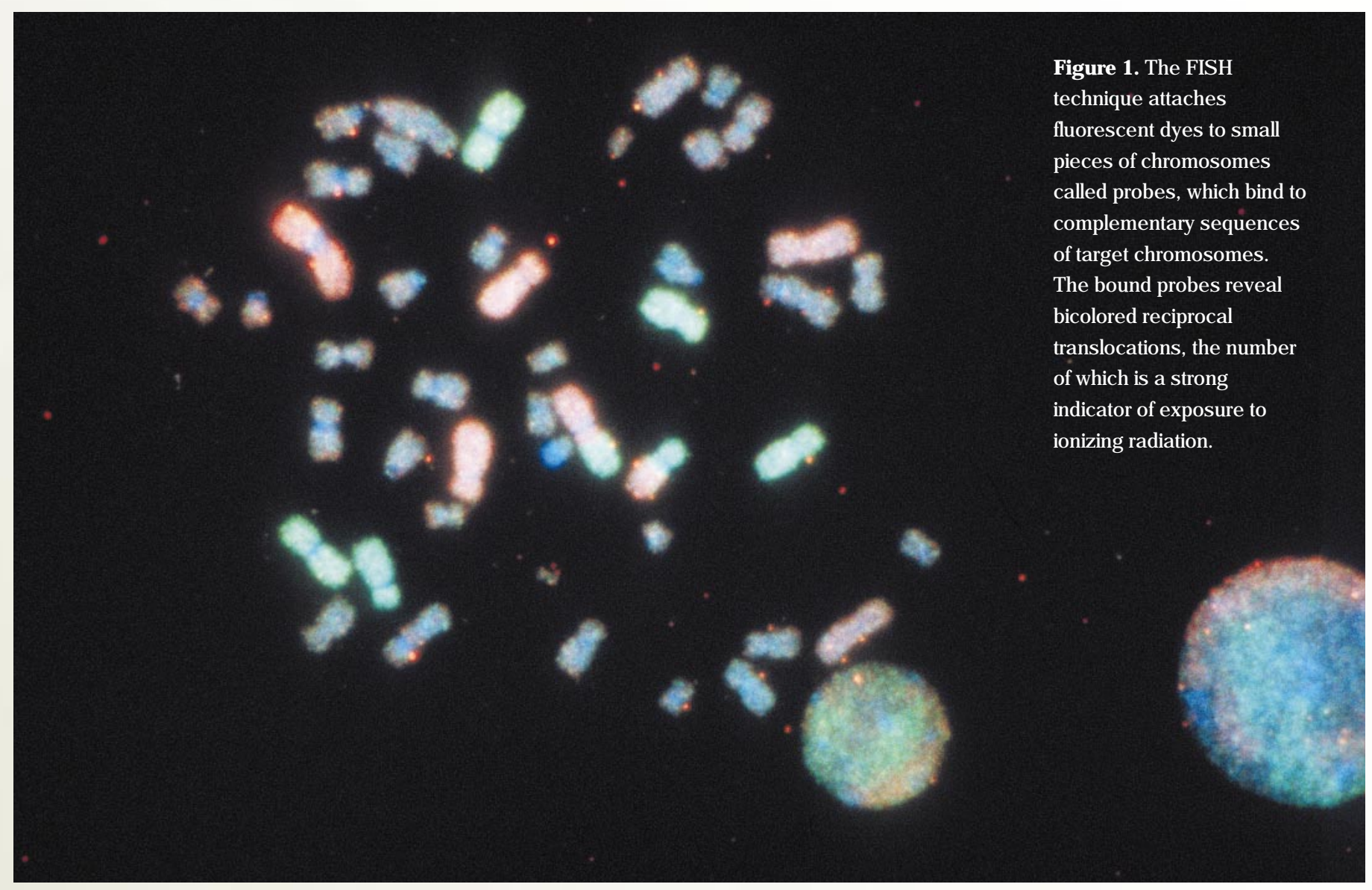

A third technique called FISH (fluorescence in situ hybridization), which was developed at Livermore and is currently used around the world, has been applied to Chernobyl liquidators as well as to others suspected of receiving ionizing radiation or of being exposed to potentially damaging chemicals. FISH measures chromosome damage by detecting the number of reciprocal translocations, or broken pieces of chromosomes, in lymphocytes that rejoin in a mismatched way. Livermore scientists have shown that the number of reciprocal translocations is proportional to exposure to ionizing radiation at low doses. What's more, unlike some biodosimeters, including other types of chromosome alterations, the frequency of reciprocal translocations is sufficiently stable with time (even over several decades) to permit retrospective dosimetry and can be measured accurately at low levels of radiation.

The FISH technique uses chromosomes from cultured lymphocytes. Fluorescent dyes are attached to small pieces of chromosome sequences called probes, which bind to complementary sequences of the target chromosomes. The bound probes reveal the extent of reciprocal translocations because they appear bicolored under a microscope using fluorescent light (Figure 1) and can thereby be counted easily to determine a person's likely exposure to ionizing radiation. (See October/November/December 1992 Energy \& Technology Review, "Chromosome Painting," pp. 11-26, and the November/December 1995 S\&TR, "The Genetic Contribution of Sperm: Healthy Baby or Not,” pp. 6-19.)

\section{Applying Biomarkers to Russian Liquidators}

The usefulness of all three biodosimeters for measuring small or moderate amounts of ionizing radiation is being demonstrated in an eight-year study (1992 to 1999) of a large group of liquidators. The study, conducted for the National Cancer Institute and directed by Livermore scientist Irene Jones, focuses on a population of about 300 Russian liquidators who were assumed to have been exposed to doses of about 5 to 25 centigrays. The study also includes 300 matched controls from Russia of about the same age and with similar smoking histories. 
Figure 2. Livermore biomedical scientists J im Tucker (second row, second from left) and Richard Langlois (second row, far right) recently visited the laboratory of Dr. Irina Vorobstova (front row, left) at the Laboratory of R adiation Genetics, Central Research Institute of R oentgenology and Radiology, St. Petersburg, Russia. Visits such as these have fostered successful collaboration on the health effects of radiation dose resulting from the Chernobyl disaster.

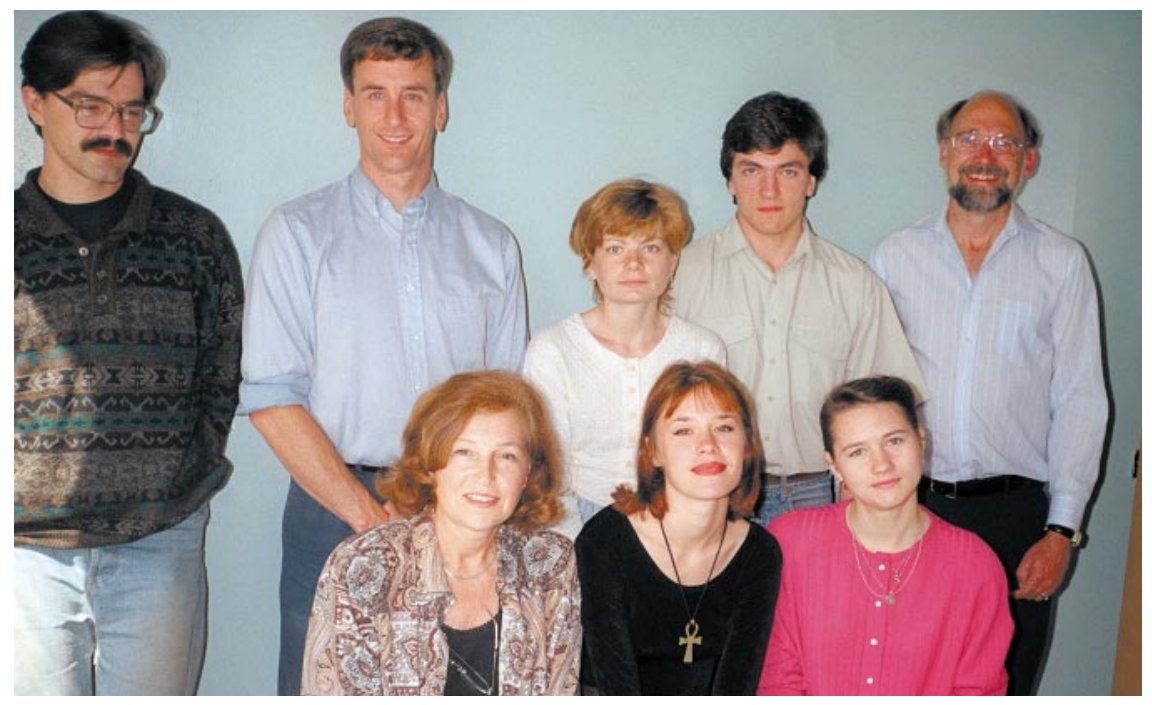

Because physical dosimetry was difficult to perform on the half-million liquidators, the Livermore team decided to estimate the Russians' exposure through biodosimetry. They also reasoned that because people have different susceptibilities to radiation toxicity, biodosimetry is a more accurate indicator of cancer risk than accurate physical dosimetry. (Physical dosimetry measures radiation incident upon the body, but biodosimetry measures cellular injury resulting from that radiation.)

\section{Recognizing Statistical Power}

Livermore experts also recognized that the large number of liquidators would give their study the same kind of statistical power that had made previous studies on Hiroshima and Nagasaki A-bomb victims important to human radiation biology. However, it would provide information for different radiation exposure conditions. While A-bomb survivors received instantaneous external exposures, Chernobyl exposures were complex mixtures of internal and external exposures over a period of time and, in some cases, during several separate work assignments.

To increase the statistical power of dose-effects studies, the Livermore investigators are collaborating with researchers from the Applied Ecology Research Laboratory, Ministry of Health and Medical Industry of Russia in Moscow; the Laboratory of Radiation Genetics, Central Research Institute of Roentgenology and Radiology, St. Petersburg, Russia (Figure 2); and the Tula Diagnostic Clinic of the Scientific Institute of Modern Medical Technologies, Tula, Russia. Blood samples are drawn in St. Petersburg, Moscow, and Tula and shipped by air to Livermore.
The results so far show FISH to be sensitive to the exposures of Chernobyl liquidators, with the HPRT assay being less sensitive and the GPA assay, which proved highly valuable for studies of A-bomb survivors and more highly exposed Chernobyl liquidators, showing no difference between the exposed and control populations (Figure 3). The Livermore team says its population of liquidators received on average a dose of about 15 centigrays, as determined by FISH. Such a radiation dose is roughly equivalent to aging about 10 years or to smoking cigarettes regularly. The expected health consequences to the population under study from such an exposure are small.

Livermore researcher Jones notes that the sensitivity to detect the effect of radiation exposure is increased by knowing the age and the smoking habits of the individual, because both characteristics contribute to the damage in their cells.

However, she says it is impossible to determine the health risk of any one individual who received a specific amount of ionizing radiation, especially at the lower doses that do not cause acute health effects. Each individual has a different complement of genes that determine how well they can repair damage from ionizing radiation and other sources. Personal habits such as smoking, drinking, and diet add to the genetic damage that accumulates in cells. "It is the sum of all damage and the body's response to that damage that determines the risk of cancer and other health effects," she says.

In a separate study led by biomedical scientist Joe Lucas, Livermore researchers applied FISH to a subset of Chernobyl liquidators suspected of receiving a large dose of ionizing radiation. They reconstructed doses for 27 Chernobyl liquidators from the frequency of translocations measured in their lymphocytes. Of the 27 individuals, 15 are 

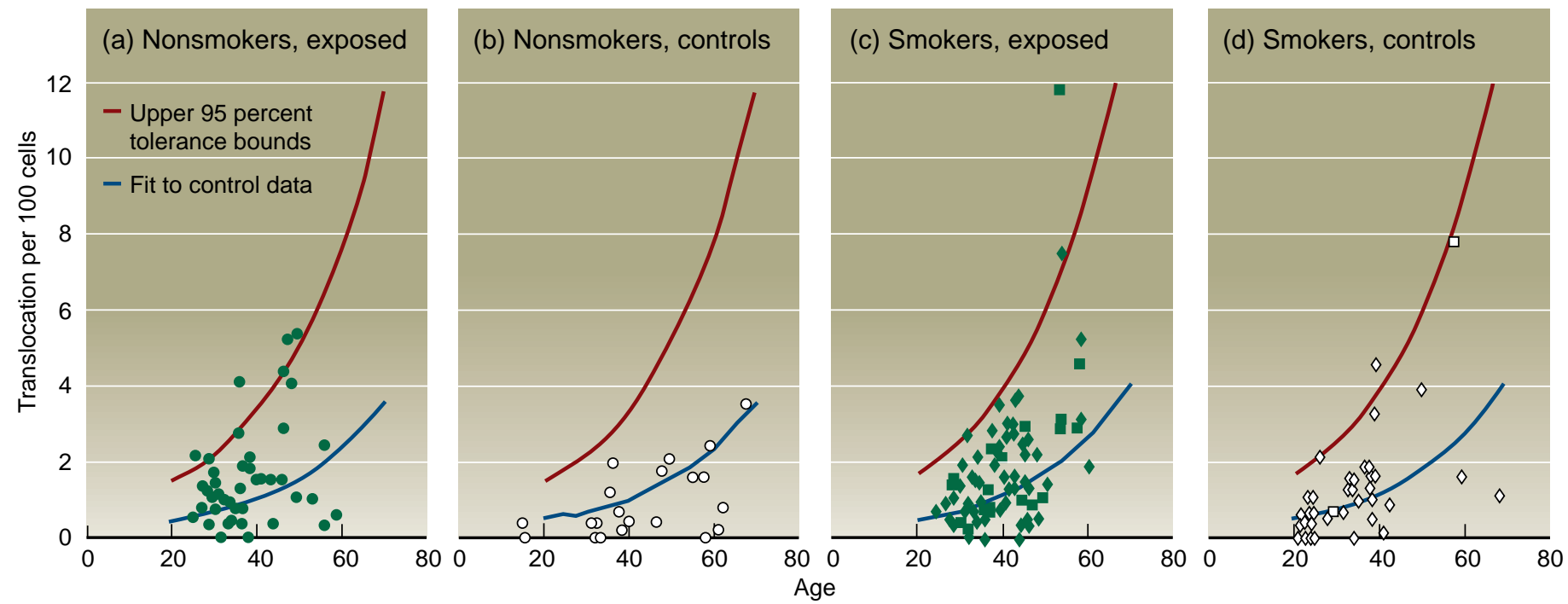

Figure 3. A Livermore study is using FISH to show that ionizing radiation from the Chernobyl accident has increased the number of chromosome translocations in (a) the liquidator population compared with (b) a control group. The FISH study also revealed the greater number of translocations seen in (c) liquidators who smoke cigarettes (solid diamonds) or a stronger tobacco called papirossi (solid squares) compared with (d) the control population of smokers (open diamonds and squares).

being treated for radiation sickness. The remaining 12 show no medical symptoms.

"FISH has worked extremely well on Chernobyl victims," says Lucas, one of the original developers of FISH. He notes that the technique is useful because not every liquidator had a dosimeter, and memories of the nature and duration of work assignments for most workers are not reliable.

\section{Questions Still Unanswered}

Current studies at Livermore and at other research centers are addressing some of the unanswered questions about the assays, such as their sensitivity to low doses, how intensity of radiation exposure affects the response, the persistence of chromosome translocations, and the degree to which factors other than radiation affect them. Jones and her colleagues, for example, are studying the extent to which the type of chromosome aberration affects its persistence in human blood cells, which could change the relationship between translocation frequency determined by FISH and radiation dose as time passes after exposure.

Another major goal of the research will be to understand why people differ in the effect that the same dose of radiation has on their cells. One part of this effort has been startedidentifying the differences in the DNA repair gene sequence in people. The next big challenge will be to determine how these differences affect the capacity to repair damaged DNA and if these differences are related to long-term health.
The Lucas group is collaborating with colleagues at Columbia University on a promising method to detect cellular damage among the liquidators. The method is based on measuring the formation of micronuclei, which are secondary and much smaller cell nuclei that form in eye cataract tissue as a result of radiation. The group is also working on an enhancement to FISH that is faster, more accurate, and more sensitive by counting individual chromosomes in liquid suspension instead of on a microscope slide.

In the meantime, Livermore radiation-effects researchers are working with collaborators in Ukraine, Russia, Estonia, and Israel (where some liquidators have immigrated) to apply biodosimeters such as FISH and GPA in their own laboratories.

It seems clear that despite its disastrous environmental consequences, the Chernobyl accident has spawned deeper understanding about the health effects of ionizing radiation and, in the process, spurred stronger international cooperation.

- Arnie Heller

Key Words: biodosimeter, Chernobyl, FISH (fluorescence in situ hybridization), glycophorin A (GPA), hypoxanthine phosphoribosyltransferase (HPRT).

For further information contact Irene J ones (925) 423-3626 (jones20@IInl.gov) or J oe Lucas (925) 422-6283 (lucas1@IInl.gov). 


\section{Target Chamber's Dedication Marks a Giant Milestone}

$\mathrm{T}$ HE June unveiling of a 130-ton (118,000-kilogram) gleaming metal sphere some 10 meters in diameter marked a much-anticipated and highly celebrated milestone for the Department of Energy's National Ignition Facility, now under construction at Lawrence Livermore. A large crowd of employees and guests, including Energy Secretary Bill Richardson, was on hand for the dedication of the giant target chamber for NIF, currently the nation's largest science construction project.

The dedication marked the on-time completion of NIF's single largest piece of equipment. The \$14.5-million vessel will serve as the working end of the largest laser in the world. The output of NIF's 192 laser beams will converge at the precise center of the chamber, where conditions of deep vacuum and temperatures far below freezing will support experiments only dreamed of for decades.

\section{Energy Secretary} Bill Richardson addresses the crowd that attended the J une 11, 1999, dedication of the National Ignition Facility target chamber. 
"There was never any doubt we could build it," says Livermore mechanical engineer Dennis Atkinson. In that respect, he says, the assignment was similar to other NIF construction projects. "They are all challenging, but we know we can accomplish them."

The engineering team, led by Livermore's Vic Karpenko and Dick Wavrik of Sandia National Laboratories, first consulted with laser scientists, optical experts, target physicists, laser physicists, and facility designers at Lawrence Livermore and Los Alamos national laboratories, the University of Rochester, and the Defense Threat Reduction Agency about their requirements for the target chamber. These requirements included the absolute synchronization of laser beams arriving at the target simultaneously, fixed focal plane distances from the final optics to the targets, close proximity of myriad instruments, and ease of ingress and egress of systems to transport, hold, and freeze the tiny targets. The result was an 11-centimeter-thick spherical vessel measuring about 10 meters in internal diameter, with 190 holes of varying diameters located over its surface to accommodate the beamlines, diagnostic instruments, and other equipment.

With the final dimensions agreed upon, the engineering team reviewed manufacturing options. One idea was to fashion the target chamber from a mosaic of small, identical (1.8- by 1.8 -meter) pieces. However, such a mosaic would require considerable on-site welding and thereby increase costs.

The team also investigated having the vessel built in a machine shop as two hemispheres and then transported to Livermore for assembly. That notion was dropped because it posed transportation problems, and the vessel, with its complicated distribution of portholes, did not lend itself to being fabricated as two equal hemispheres.

\section{Giant Volleyball}

The team finally agreed upon an expanded cube (6 sides) with 3 plates per side (18 plates total) to minimize welding length and overall cost. The design, looking like a giant volleyball, features 6 symmetric middle plates and 12 asymmetric outer plates. As manufactured, the 18 aluminum plates measure 2.4 by 6.9 meters and weigh about 7.5 tons each.

There was uniform agreement that the vessel should be manufactured from aluminum, specifically the aluminum alloy 5083-0. The same alloy, notes mechanical engineer Wavrik, is used in harsh marine environments such as ship superstructures.

The completed vessel was estimated to weigh some 130 tons. An outer concrete skin and final optics would add 200 tons each, for a total of nearly 530 tons. Given that estimate of final weight and the number of holes that needed to be drilled, the designers decided on a plate thickness of
11 centimeters. Although this was more than was needed theoretically, it gave the chamber the strength of a substantial structure in its own right rather than a simple vessel to contain experiments.

A prime consideration was ease of fabricating the 18 plates. "We wanted to make sure we didn't design something that would be difficult to manufacture," says Atkinson. The team chose as manufacturing contractor Pitt-Des Moines Inc., which has extensive experience fabricating vessels, from nuclear power plants to water storage tanks.
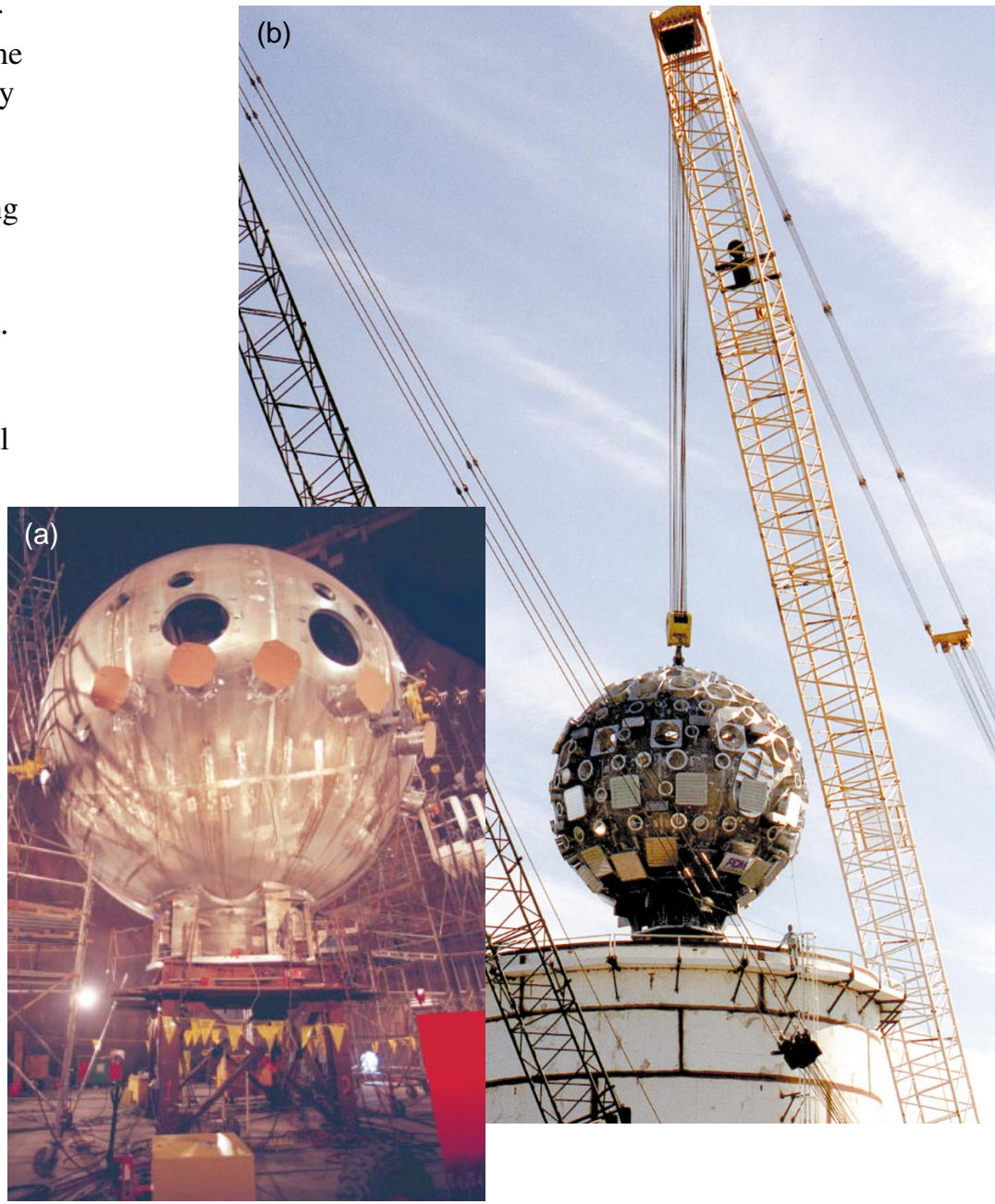

(a) The target chamber being assembled within a temporary cylindrical steel structure with a removable roof. This progress photograph was taken in March 1999 when all of the plates making up the chamber were in place and some of the 190 portholes to accommodate beamlines and diagnostic instruments had been cut in it. (b) The completed target chamber being removed from the temporary assembly structure. 
Pitt-Des Moines assembled an international team of subcontractors. Manufacturing began in the fall of 1997, when the plates were poured at the Ravenswood Aluminum Mill in Ravenswood, West Virginia. The plates were shipped to forming subcontractor Creusot-Loire Industries in France, where the plates were heated to $315^{\circ} \mathrm{C}$ and then shaped in a giant press to the proper spherical geometry.

\section{From France to Pennsylvania}

The formed plates were shipped weekly in pairs from France to Precision Components Corp. in York, Pennsylvania, where they were trimmed and weld joints were prepared. Three plates at a time were trucked to Livermore. The first plates to arrive were those with the highest tensile strength to provide a strong base for the entire vessel.

Assembly and welding activities at Livermore were performed in a temporary cylindrical steel enclosure looking much like an oil or water tank. Constructed in June 1998, the temporary structure measured 18.3 meters in diameter and 18.9 meters high and rested on a 61-centimeter-thick concrete slab. The enclosure featured a roof to ensure temperature control and keep out rain. The roof was removed only to permit cranes to lift the plates into place as soon as they arrived and for lifting out the assembled vessel for its dedication and transport to its final home in the target building.

After the bottom three plates were welded together to form a supporting base, the other plates were lowered into place and held together with guy wires until welded. Each welded seam required 150 passes over a like number of layers of thin aluminum wire for a smooth, nonporous finish. Although time-intensive, this approach minimized thermal stress to the aluminum plates.

The porthole drilling process required laser instrumentation both to mark the port location and to drill the pilot holes. Most of the ports are arranged in pairs, one directly on the opposite side of the chamber from the other. In this way, the two opposing ports may be used for alignment purposes.

Seventy-one larger holes 1.16 meters in diameter will accommodate the final optics assemblies (FOAs), the last element of the main laser system. An additional port, which includes an FOA port, measures 1.67 by 1.16 meters and provides access for testing nuclear-weapons effects. (Designers have provided the capability to receive and transport a large diagnostic package to this port.) Weldnecks with thick flanges were secured to the ports to accommodate the optics assemblies, which will be bolted to the weldnecks.

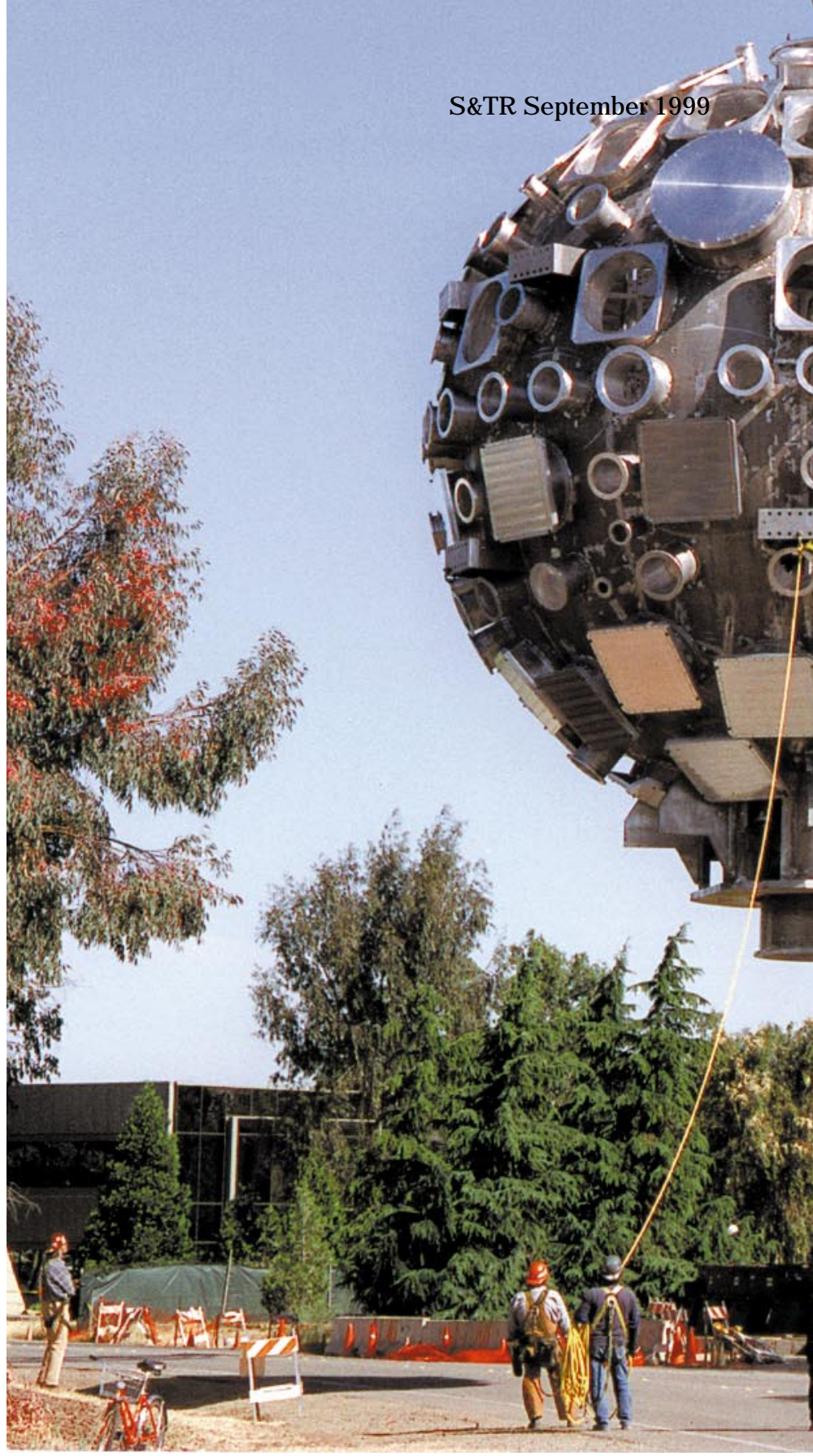

In addition, workers drilled 118 diagnostic-instrument ports with inner diameters varying from 15 to 70 centimeters.

\section{Achieving Extreme Sphericity}

At regular steps along the way, the chamber was mapped with laser surveying instruments to ensure its sphericity. Wavrik notes that the American Society of Mechanical Engineers specification for spherical vessels is for the diameter to measure within 1 percent of specification, or within 10.16 centimeters for the 10-meter-diameter chamber. The Livermore-Sandia 


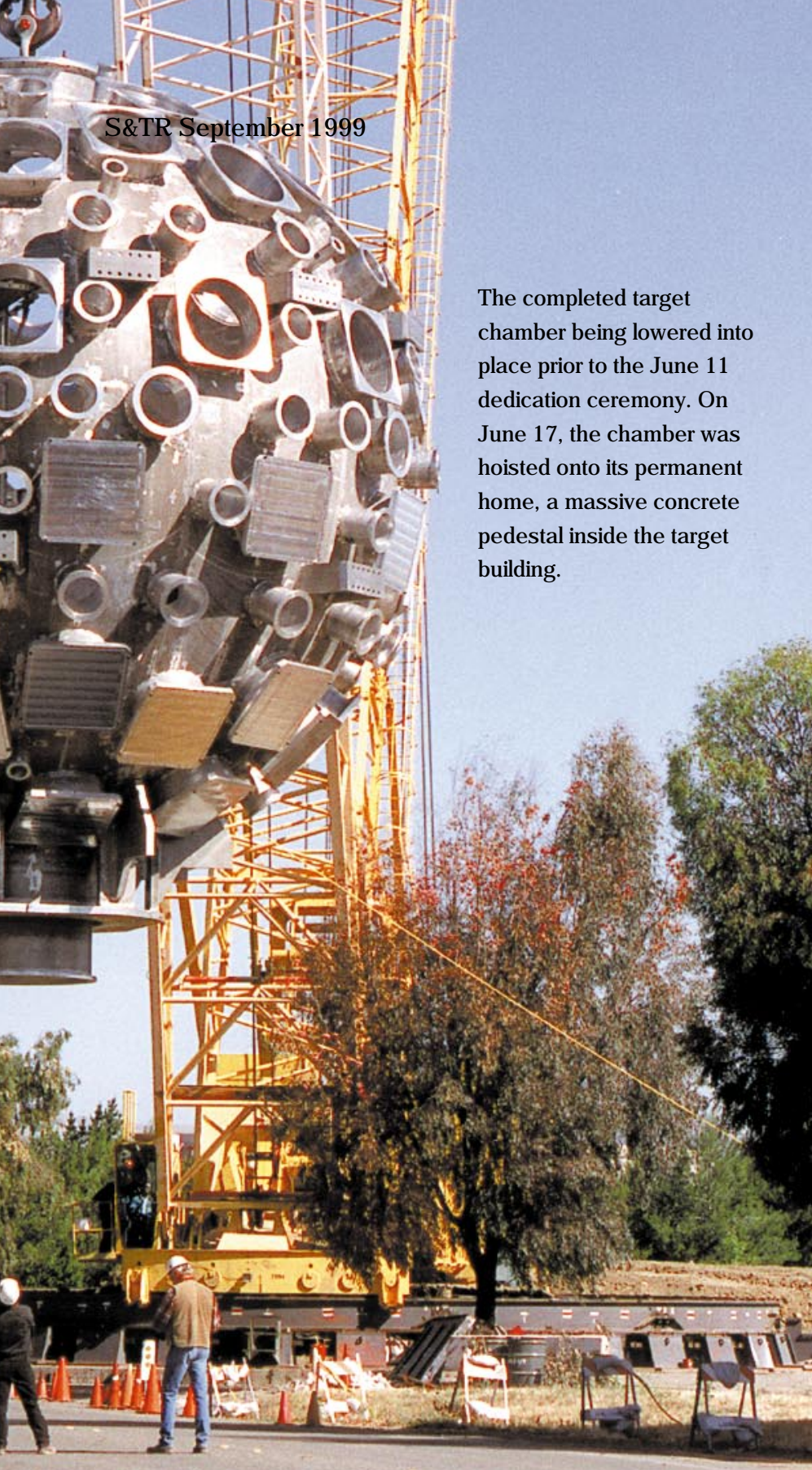

specifications called for final measurement within 0.5 percent, or 5.1 centimeters in 10 meters. In fact, the assembly crew achieved 0.25 percent, or 2.54 centimeters, across the entire diameter.

On June 5, the roof of the temporary enclosure was removed, and the target chamber was lifted out by an enormous crane, a 14-story-tall Manitowoc 4600 Ringer. Acquired from DOE's Nevada Test Site (and transported in pieces aboard 66 trucks), the crane weighs some 900 tons and has a lift capacity of 600 tons. It will remain on site for additional heavy-lifting construction jobs on NIF.
The sphere was secured to the crane with a plate lowered vertically into the top port of the sphere and then turned horizontally to support the chamber from inside (similar to installing a togglebolt). "We all held our breath," recalled Livermore Director Bruce Tarter, when the chamber was lifted out of the enclosure and then placed on a Lampson Crawler (also borrowed from the test site) as an intermediate anchor for its public dedication.

A few days later, on June 11, the world got a good look at the chamber at the dedication ceremony. The extraordinary structure became an instant magnet for employees and visitors alike. As Britain's Graham Jordan, Deputy Under Secretary for Science and Technology, Ministry of Defense, remarked, the chamber looked as if it "simply landed one night" from outer space.

The following week, the chamber was hoisted onto a massive concrete pedestal installed inside the target building. Over the next two weeks, a combination of hydraulic jacks, roller assemblies and shims, and finally anchor bolts were used to adjust the chamber for final alignment and establish its proper elevation and sphere tilt.

This fall the exterior of the chamber will be tested for leaks and then encased in 40 centimeters of concrete with 0.1 percent boron to provide shielding from the neutron and gamma rays produced by the experiments. The concrete will be applied over steel rebar tied to the chamber with welded studs.

Following application of the concrete, the chamber's exterior will be sealed with epoxy paint, and the chamber

will be aligned and hung with the final optics assemblies, which will arrive next year. The chamber is expected to sag a bit from the 400 tons of the concrete shield and optics. As a result, the angle of the FOAs will be adjusted appropriately.

Although an unqualified success in its own right, the target chamber's completion serves as a striking symbol that NIF is only a few years away from history-making experiments as an essential component of DOE's Stockpile Stewardship Program.

-Arnie Heller

Key Words: final optics assemblies (FOAs), hohlraum, National Ignition Facility (NIF) target chamber, Nevada Test Site, Stockpile Stewardship Program.

For further information contact Dennis Atkinson (925) 422-6984 (atkinson2@IInl.gov) or Dick Wavrik (925) 422-0415 (wavrik1@llnl.gov). 
Each month in this space we report on the patents issued to and/or the awards received by Laboratory employees. Our goal is to showcase the distinguished scientific and technical achievements of our employees as well as to indicate the scale and scope of the work done at the Laboratory.

\section{Patents}

Patent issued to

Daniel M. Makowlecki

Alan F. J ankowski
Patent title, number, and date of issue

Method of Fabricating Boron Containing Coatings

U.S. Patent $5,897,751$

April 27, 1999

\section{Summary of disclosure}

A method for fabricating boron nitride, cubic boron nitride, and multilayer boron/cubic boron nitride hard coatings using magnetron sputtering in a selected atmosphere. These hard coatings may be applied to tools, electronic divices, and engine and other parts to reduce wear on tribological surfaces. These boron coatings contain no morphological growth features. For example, the boron is formed in an inert (for example, argon) atmosphere, while the cubic boron nitride is formed in a reactive (for example, nitrogen) atmosphere. The multilayer boron/cubic boron nitride is produced by depositing alternate layers of boron and cubic boron nitride, with the alternate layers having a thickness of 1 nanometer to 1 micrometer. The interfaces of the layers may be discrete or of a blended or graded composition.

$\begin{array}{ll}\text { Steven T. Mayer } & \text { Capacitor with a Composite Carbon } \\ \text { Richard W. Pekala } & \text { Foam Electrode }\end{array}$

J ames L. Kaschmitter

U.S. Patent $5,898,564$

April 27, 1999

Edward J . Kansa

Brian L. Anderson

Ananda M. Wijesinghe

Brian E. Viani

\begin{abstract}
Separation of Toxic Metal Ions, Hydrophilic Hydrocarbons, Hydrophobic Fuel, and Halogenated Hydrocarbons and Recovery of Ethanol from a Process Stream
\end{abstract}

U.S. Patent $5,906,748$

May 25, 1999
Carbon aerogels used as a binder for granularized materials, including other forms of carbon and metal additives, are cast onto carbon or metal fiber substrates to form composite carbon thin-film sheets. The thin-film sheets are used in electrochemical energy storage applications, such as electrochemical double-layer capacitors (aerocapacitors), lithium-based battery insertion electrodes, fuel-cell electrodes, and electrocapacitive deionization electrodes. The composite carbon foam may be formed by prior known processes, but with the solid particles being added during the liquid phase of the process, that is, prior to gelation. The other forms of carbon may include carbon microspheres, carbon powder, carbon aerogel powder or particles, and graphite carbons. Metal and/or carbon fibers may be added for increased conductivity. The choice of materials and fibers will depend on the electrolyte used and the relative tradeoff of system resistivity and power to system energy.

A process to greatly reduce the bulk volume of contaminants obtained from a subsurface remediation using an effluent stream. The chemicals used for the subsurface remediation are reclaimed for recycling to the remediation process. Additional reductions in the bulk volume of contaminants are achieved by destroying the halogenated hydrocarbons with ultraviolet light and by the complete oxidation of hydrophobic fuel hydrocarbons and hydrophilic hydrocarbons. The contaminated bulk volume will arise primarily from the disposal of the toxic metal ions. The entire process is modular, so if there are any technological breakdowns in one or more of the component process modules, such modules can be readily replaced.

\section{Awards}

Livermore scientist Steve Gray has received the Defense Intelligence Agency Director's Award for his exceptional leadership in setting up a sophisticated Web site on a classified, secure network that combines up-to-date information on foreign proliferation with computational tools and models.

The program, named Dragon Fury, is now running on a classified network available to Department of Defense policymakers, the intelligence community, and war-fighting commanders. The Defense Intelligence Agency (DIA) runs the Department of Defense's military intelligence operations.
According to the award citation, "Mr. Gray's dedication to the Dragon Fury Program has made it possible for senior-level defense policymakers, military planners, and combat commanders to access comprehensive, accurate, and timely information in order to perform their counterproliferation planning and execution missions. His consistently outstanding leadership and performance have brought great credit upon himself, the Lawrence Livermore National Laboratory, and the Defense Intelligence Agency."

Gray is believed to be the first non-DIA employee to receive this award. 


\section{Coming Next}

A Better Picture of Aging Materials The shelf life of a nuclear weapon was not an issue until the early 1990s when the U.S. stopped developing and testing nuclear weapons. Existing weapons are expected to remain operational for several decades beyond their originally designed lifetime. Livermore is studying the aging processes of the many materials that make up a nuclear weapon, such as high explosives, metals, and organic materials, with the goal of developing models that predict the lifetime of individual materials as well as of the entire weapon system. Some experiments are examining the fundamental nature of the materials, while others are studying weapons taken from the stockpile to see how aging is progressing. The process of compiling this data into predictive models is just beginning. Contact: J ames LeMay (925) 423-3599 (lemay1@IInl.gov).

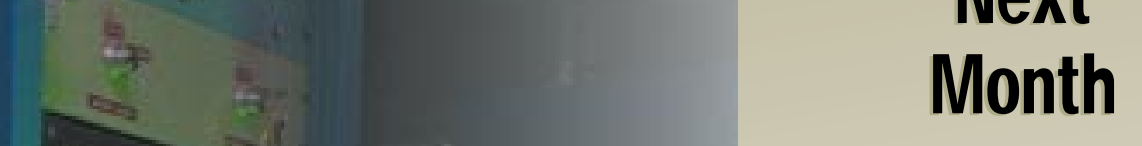

Liver mor e Wins Six R\&D 100 Awards

In October, S\&TR will report details about the winning inventions and the teams that created them.

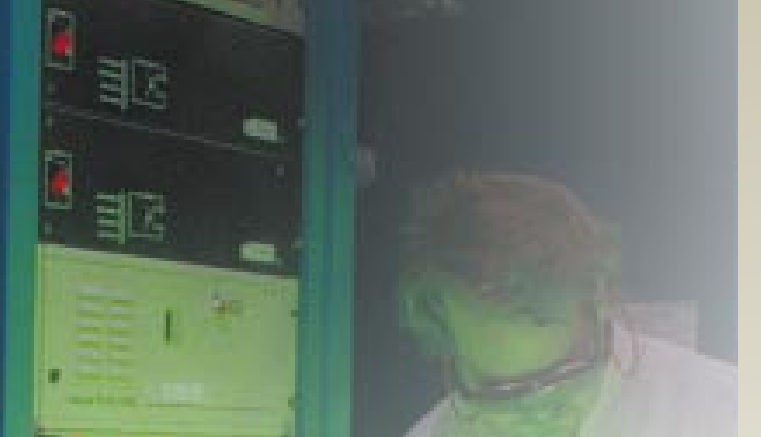

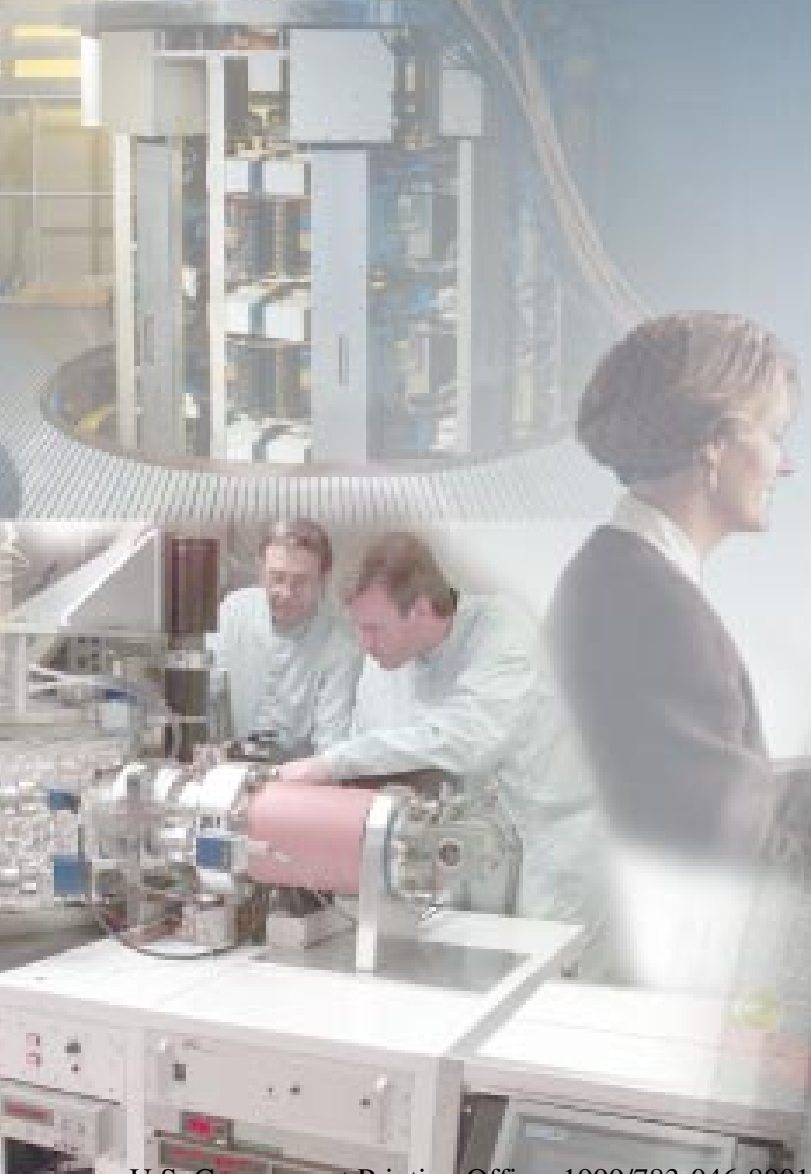


(1) Printed on recycled paper.

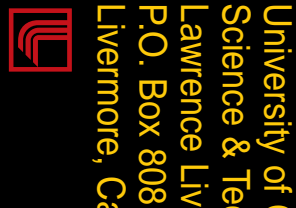
요

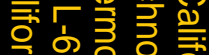
을 용응 응 흑 ㅁำ

$\infty$ ग 봉 옹

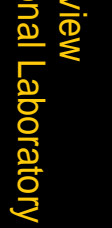

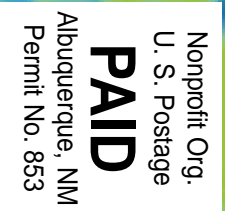

